\title{
Workspace analysis of 3-DOF U-shape base planar parallel robotic motion stage using shape memory alloy restoration technique (SMART) linear actuators
}

\author{
Deep Singh $^{1}$ (D) Rutupurna Choudhury ${ }^{2} \cdot$ Yogesh Singh $^{2} \cdot$ Manidipto Mukherjee $^{3}$
}

Received: 19 September 2020 / Accepted: 9 March 2021 / Published online: 29 March 2021

(c) The Author(s) 2021 OPEN

\begin{abstract}
The applications of lightweight planar parallel robotic manipulators are increasing enormously because of its various desirable characteristics such as low weight, lower inertia and higher stiffness. Higher accelerations and accuracies can be achieved in planar parallel manipulators. Also, shape memory alloy restoration technique (SMART)-based linear actuators are replacing huge and bulky linear actuators. This study presents the kinematic design of smart linearly actuated family of $\mathrm{U}$-shape base planar parallel robotic manipulator. With the aid of solid modelling software, different available configurations were modelled and their workspace was analysed. The developed 3-DOF motion stages (18 unique configurations) were fabricated using fused deposition modelling process, and the top three configurations having higher workspace were further experimented. It is interesting to observe that the actual or experimental workspace of a particular manipulator configuration is further minimised from the predicted or feasible workspace. It is due to the presence of passive links, singularities, friction between the parts, heat dissipation, force distribution, stiffness, etc. The present study depicts the experimental workspace of the top three configurations, namely PPR-PRP-PRR, $\underline{P R P}-\underline{P} P R-\underline{P} R P$ and PRP-PPR-PRR. Since none of the experimental workspace observed is equal or higher than the model workspace, an efficiency loss in terms of workspace reduction was calculated to understand the acceptability of the configurations in different domains. Apart from the loss, the result disclosed that the actual workspace of all the manipulators was within the feasible workspace domain of mobile platform. The PPR-PRP-PRR manipulator was found to possess highest experimental workspace than other configurations. Note: $P, P$, and $R$ refer to active prismatic, passive prismatic and passive revolute joints respectively.
\end{abstract}

Keywords Nitinol · Micro-positioning · Planar parallel manipulators (PPMs) · Shape memory alloys

\section{Introduction}

Currently, robotics has gained numerous applications in almost every field. The need to automate various tasks in different robotic applications triggers the need for research. Numerous researches have been conducted based on applications and still seem to be an endless research field, as it gains enormous importance. Till date, distinct robotic manipulators have been studied and still, numerous kinds are being proposed and studied in order to automate and thus reduce human effort. The notion of parallel manipulators is well recognized and well developed [1-3]. Today, parallel manipulators have a wide variety of applications covering fields such as medical,

Supplementary Information The online version contains supplementary material available at https://doi.org/10.1007/s42452-021-04490-y.

Deep Singh, deepsingh_dh@srmuniv.edu.in | 'Department of Mechanical Engineering, SRM Institute of Science and Technology, Chennai, Tamil Nadu, India. ${ }^{2}$ Department of Mechanical Engineering, National Institute of Technology Silchar, Silchar, Assam, India. ${ }^{3}$ Advanced Manufacturing Centre, CSIR-Central Mechanical Engineering Research Institute, Durgapur, West Bengal, India. 
automotive, aerospace, military and space sectors. Parallel manipulators are greatly being applied for various other purposes such as cutting, welding, material handling, grinding, ship building, inspection, oil-well firefighting, ship-to-ship cargo handling, bridge construction, aircraft maintenance and steel erection [4].

Singh et al. proposed a five degrees of freedom based robotic manipulator which serves as goalkeeper in order to train football players [5]. The kinematic and dynamic study was carried out along with the torque analysis. Stewart platform, the well-known six-degree-of-freedom (DOF) spatial manipulator, has few limitations including a small and complex workspace, restriction of orientation angle and complex kinematics and dynamics system [6]. For these reasons, researchers begin to pay their attention to use lower-degree-of-freedom-based parallel manipulators, namely planar parallel manipulator (PPM). Parallel manipulators are also known as closed-loop manipulators [4]. The movement of PPM is restricted to a plane using prismatic and revolute joints [1-3, 7-39].

Despite being more workspace and dexterous manoeuvrability in serial robotic manipulators, PPMs gain more popularity and usage in real applications. This is because of the cantilever structure of the serial manipulators which leads to bending and also produces vibration at high speed which degrades the precision of the manipulators [4]. Parallel manipulators can take up more load as the entire load is shared by the parallel members and also provides more rigidity and stiffness with lesser inertia [4]. Also, the parallel manipulators undergo only compressive or tensile loads and no shear forces, bending and torsion moments [4]. Because of lower inertia, the parallel manipulators are also used for the purpose of flight simulators and fast pick-and-place robots $[4,40]$. Parallel manipulators are more accurate as the errors are averaged as compared to serial robots in which errors are summed. It is because of the closed-loop architecture of the parallel links [4]. Despite parallel manipulators resulting in multiple inverse kinematic and direct kinematic solutions, it also provides more flexibility for the purpose of trajectory planning [41].

PPM consists of at least three limbs (kinematic chains) forming a mobile platform which is coupled to a fixed base by means of at least three limbs comprised of prismatic/ revolute joint $[7-39,42]$. These planar parallel motion stages have numerous applications, including material micro-machining, processing, material handling, fabrication, telescoping positioning systems and many more because of more straightforward joint arrangements [42]. In the past, many configurations such as 3-RRR, 3-PRR,

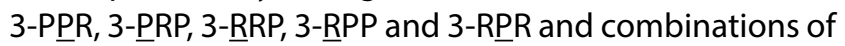
different limb configurations such as $\underline{P} R P+\underline{P} P R+\underline{R} R R$ have been proposed. Each configuration has its advantages and limitations [1, 7-39]. Most of the designs for planar parallel manipulators are based on symmetric topology as it enhances the structural stiffness along with the manufacturing and assembly simplicity.

The kinematic analysis of three-degree-of-freedom 3-RRR planar parallel robotic manipulator has been studied by Chablat et al. with symmetric properties. Parallel manipulators exist with multiple direct kinematic solutions [41]. Since the stiffness of parallel manipulators plays an important role in deciding the positioning and orientation accuracies, Guanglei et al. [43] introduced a numerical method to decouple the Cartesian stiffness matrix into two and analysed it differently using eigenvalue problem to determine the manipulator stiffness for the 3-PPR PPM. The manipulator was studied under the influence of nonlinear actuation compliance [43]. Bai and Caro et al. proposed a 3-PPR PPM with an unsymmetrical base to maximize the robot's workspace. The manipulator results in amazing facts of decoupled degrees of freedom and large orientable workspace [44]. Gosselin and Angeles studied the kinematics of 3-RRR parallel manipulators to maximize the workspace [45].

The equilateral triangular base-based symmetric planar parallel robotic manipulator provides higher structural stiffness but may not deliver larger workspace, compactness, modularity and simple structure. To overcome the limitations, a new family of 3-DOF planar parallel manipulator was proposed. The proposed family of PPM is comprised of three limbs mounted on the base of a square or ' $U$ ' shape. The first joint of each limb is the active prismatic joint, and the SMART actuator was used for bidirectional linear actuation [46].

AbuZaiter et al. [47] have developed a miniaturized Stewart platform which actuates using TiNiCu-based SMA actuators. It provides translational motion along z-axis along with tilting motion using 4 SMA springs. AbuZaiter et al. [48] also developed a SMA-actuated micro-positioning stage using six SMA springs. The developed stage possesses 3-DOF to move smaller objects for microscopic scanning applications. Sreekumar et al. [49] presented the development of a compliant parallel manipulator actuated by SMA wire. The experiment resulted large deflection analysis, and the device is suitable for various applications in space, medical, etc. Santhakumar et al. [50] studied the forward and inverse kinematics along with the workspace of three-legged U-shape base 3PRP planar robotic manipulator experimentally by implementing nitinol spring, a shape memory alloy (SMA), as an actuator. The nitinol serves as a linear actuator and actuates on the supply of electrical current across it. The end-effector pose and the workspace of the manipulator were analysed in the absence of a feedback loop (open-loop condition). Deep 
et al. [51] have also presented the experimental workspace associated with the U-shape base 3ㄹP, $\underline{P} P R-2 \underline{P} R P$ and PRR-PRP PPMs incorporating SMART actuator. Although the performance of few of the PPMs is evaluated, there is a need to identify the significance of each of the eighteen U-shape base PPMs as discussed in Sect. 2. The workspace, singularity and kinematic isotropy associated with each of the discussed PPMs vary due to the variation in the design of each limb. Hence, identification of workspace associated with the manipulators can highly influence its application in a wide domain of micro-manufacturing, micro-fabrication, etc.

In the present study, the workspace associated with the family of U-shape 3-DOF PPM is analysed by the smart actuation technique of the active input translational joints. The smart actuation refers to the implementation of SMAbased smart material actuator, here referred to as a SMART (shape memory alloy restoration technique) linear actuator. Each of the eighteen U-shape base PPMs is evaluated for the associated workspace, and each of the manipulators can be implemented for a variety of applications based on its work region.

\subsection{Shape memory alloy restoration technique (SMART) linear actuator}

SMAs are one of the most wonderful materials because of its ability to memorize shapes due to thermally induced solid-state phase transition. The composition of SMA helps in providing different mechanical characteristics such as ductility, corrosion and also memory [52]. SMAs are very unique materials that changes its shape, position, stiffness, natural frequency and various other mechanical properties with the variation in temperature. Because of such unique mechanical behaviour, SMAs are hugely studied $[53,54]$.

SMA has gained much importance in the application as actuators because of its high energy density, clean and silent actuation. The phase transformation in an SMA takes place between a low crystallographic symmetry (monoclinic crystal structure) martensitic phase to a high symmetry (cubic crystal structure) austenitic phase under thermal loading. At low temperatures and high stresses, the martensite shows stability, and at high temperatures and low stresses, the austenite shows stability [51,52]. Some of the SMAs are $\mathrm{Cu}-\mathrm{Zn}, \mathrm{Cu}-\mathrm{Al}-\mathrm{Ni}, \mathrm{Ni}-\mathrm{Ti}, \mathrm{Ni}-\mathrm{Ti}-\mathrm{Fe}, \mathrm{Cu}-\mathrm{Zn}-\mathrm{Al}$, $\mathrm{Fe}-\mathrm{Pt}$ and many more.

Nitinol (NiTi), a shape memory alloy, exhibits the characteristics shape memory effect (SME) and super-elasticity depending on the working temperature. The composition of nitinol is $50 \%$ nickel and $50 \%$ titanium. The maximum recoverable strain is fixed for a fix SMA. However, applying higher stress also induces more elastic strain [55]. Nitinol is comparatively better than the CuZnAl and CuAINi based on multiple thermo-mechanical performances, including biocompatibility $[54,56]$. SMA actuators are gaining huge popularity as they are very compact with higher power/ mass ratio and low voltage activation [54]. One of the main characteristics of SMA is hysteresis which makes complications in controlling the displacement because of its continuous nonlinear variation in length. The difference between the forward and reverse transformation paths results in hysteresis [57].

The SMA-based actuators can be operated by the Joule heating process. On supply of direct current (DC) across the SMA, the temperature of the actuator rises due to the presence of electrical resistance of the SMA-based wire and springs. Due to the increase in temperature, the SMA-based actuators (at the pre-stretched condition) undergo a phase transformation from martensite to austenite resulting in contraction (or torsion, in case of springbased SMA) of the SMA. The rate of contraction increases with the rise in value of the current and vice versa. Singh et al. have also categorized the current into four based on the actuation and precision attained by the Nitinol SMA spring, as depicted in Fig. 1 [53]. ' $V_{c}^{\prime}$ represents the rate of contraction of the spring (or rate at which the overall length of the spring decreases) against each category, for a change in length (or retraction) of $71 \mathrm{~mm}$ (pre-stretched initial length $=100 \mathrm{~mm}$, final length $=29 \mathrm{~mm}$ ). Recently, SMAs are being used in various fields such as biomedical, commercial and aerospace industries. DesRoches et al. [58] studied the potential of Ni-Ti SMA for application in seismic-resistant design and retrofit. Khidir et al. [59] presented a technique and its feasibility to actuate PPMs using SMA-based linear actuators.

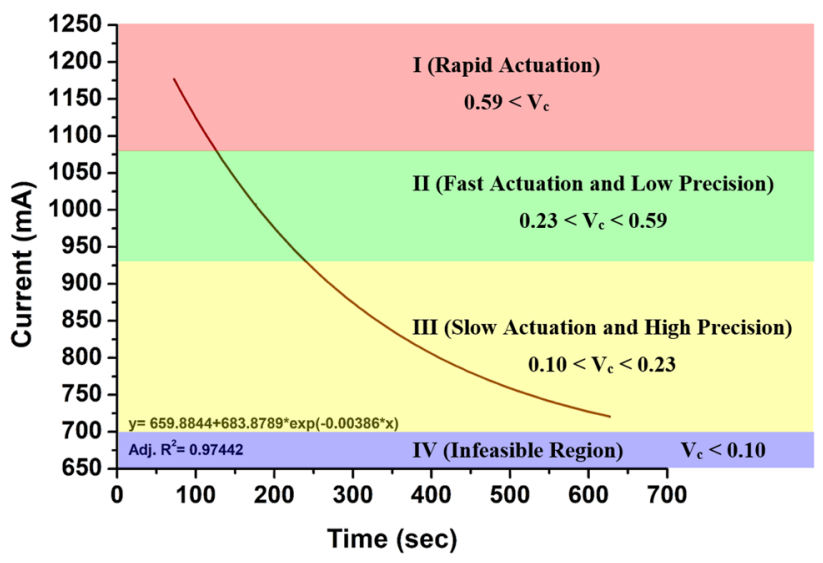

Fig. 1 Exponential plot of current vs. time for contraction of prestretched nitinol spring [53] 


\section{Family of U-shape base planar parallel manipulators}

The family of U-shape base PPMs possesses three legs (limbs) of which one is oriented along the $X$-axis and the other two oriented along the $\mathrm{Y}$-axis, forming the fixed base of the shape ' $U$ '. In this respect, it is possible to develop a PPM with three limbs using eight serial (open-loop) limbs, namely PPP, PPR, PRP, PRR, RRR, RPR, RRP and RPP. The first joint at each limb of the 3-DOF planar parallel manipulator is considered to be an active prismatic joint $(\mathrm{P})$ because of its multiple advantages such as modular design, back drivability, compactness, reduction in the link interferences, large singularity-free workspace, simple kinematic arrangement, ease of control and low inertial properties of the moving system $[1-3,16,60]$. Hence, out of the above-mentioned eight kinematic limbs, only four limbs could develop a U-shape base 3-DOF PPM, namely PPP, PPR, PRP and PRR. Out of these four limbs, PPP limb is avoided to develop 3-DOF PPM as it does not allow rotation to the mobile platform (end-effector) of the manipulator. Therefore, only three limbs, namely PRP, PPR and PRR, are feasible for implementation in the manipulator. Thus, based on repetition theory of permutation and combination, three limbs (PRP, PPR and PRR) are implemented to develop 3-DOF PPM which leads to $3^{3}=27$ manipulators as represented in Fig. 2. However, it can be clearly seen that 9 out of

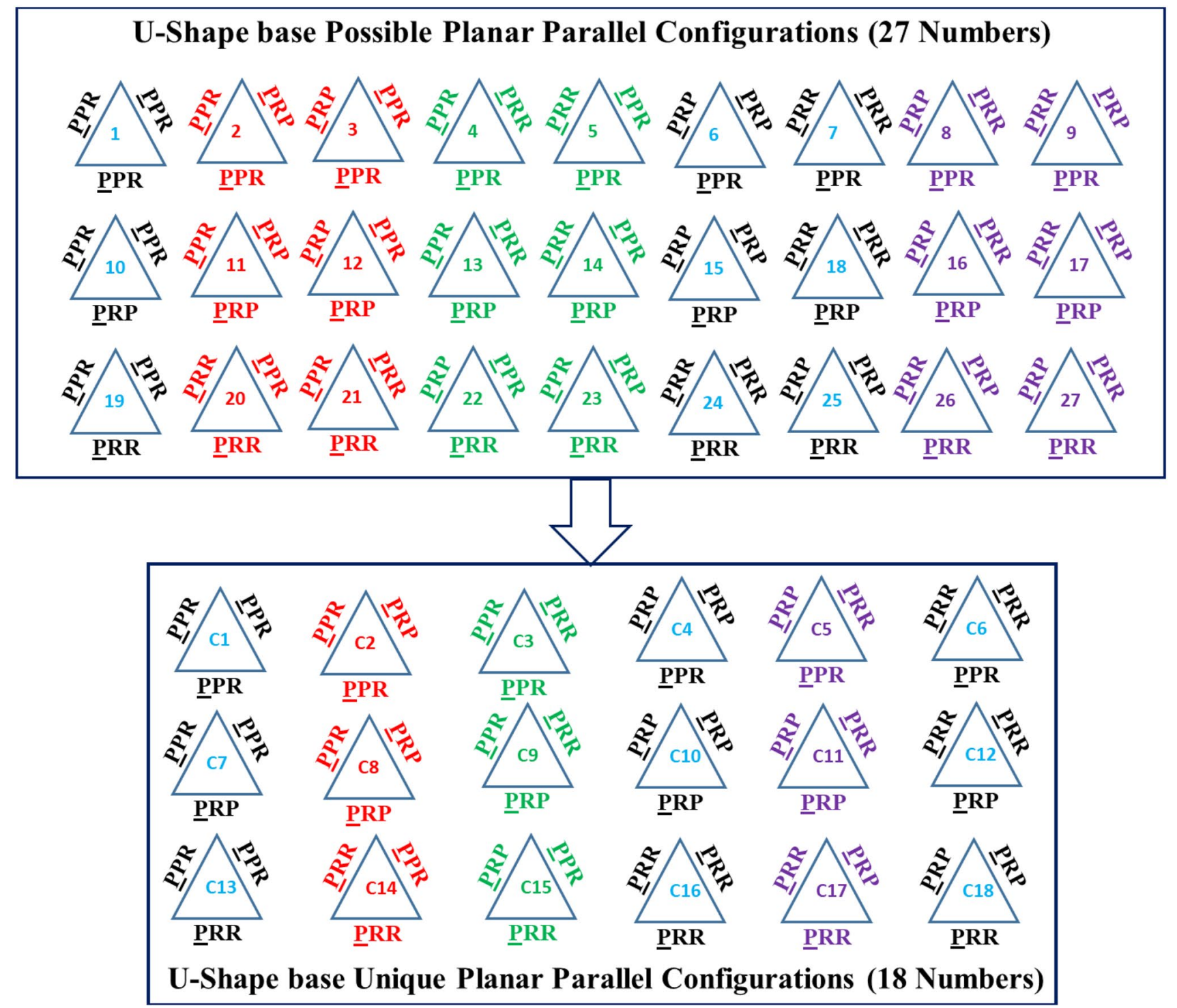

Fig. 2 Family of U-shape base planar parallel manipulator

SN Applied Sciences 
27 manipulators are repeated which results in 18 unique and non-repetitive manipulators as illustrated in Fig. 2 [51]. The nomenclature of the manipulators has been presented uniquely, as represented in Fig. 2. The letter ' $C$ ' stands for 'Configuration' followed by the manipulator number such as $\mathrm{C} 1, \mathrm{C2}, \mathrm{C} 3$ and so on. This nomenclature is short and helps in easy referencing in the paper. Each manipulator in the proposed ' $U$ ' shape family possesses 3-DOF with the configuration of the end-effector given as $\left(x, y, \theta_{z}\right)$.

These manipulators will, however, be applied in the implementation of different applications depending on the workspace associated with each manipulator. Therefore, it is important to define the workspace for each manipulator. This study introduces the workspace analysis correlated with each manipulator. Every limb of this family of manipulator begins with an active prismatic joint followed by passive joints and links which connects fixed base to the end-effector.

A very effective tool for determining the workspace is the kinematics of a parallel manipulator. In addition, it is very difficult to design and control the manipulator without the kinematic solution or the workspace [42].

\section{Geometrical and kinematic arrangements of the family of U-shape base manipulators}

The frame arrangement of the fixed and mobile platform is denoted by ' $O$ ' and ' $Q$ ', respectively. These frames play a crucial role in describing the kinematic solution of the manipulator through the associated link and joint parameters.

The shape of the end-effector considered is an equilateral triangle of side length ' $a$ ' and height ' $h$ ' connected to the fixed U-shape base platform by three limbs. Active joint displacement is denoted by ' $r_{i}^{\prime}(i=1,2,3)$. The link length of the connecting members connecting the active prismatic joint and the end-effector is denoted by ' $l_{j}^{\prime}$ $(j=1,2,3)$. 's' and ' $h$ ' are the width and height of the fixed $\mathrm{U}$-shape base, respectively. The orientation (rotation about the $z$-axis) of the mobile platform is denoted by ' $\theta_{z}$ ' , and the design angles of the configurations are denoted by ' $\theta_{k} \cdot(k=1,2,3,4)$.

Figure 3 depicts the kinematic configurations of limbs PPR, PRP and PRR. Figure 3 also provides the correlation between the active translational joint and the pose of the end-effector under various conditions like the same or different limbs associated with the development of a 3-DOF PPM. All the active controllable inputs are considered as active prismatic (translational) inputs for the design and analysis.
Jacobian matrix $(\mathrm{J})$ of any configuration (18 manipulators) refers to the velocity transformation/mapping matrix which maps the Cartesian space velocities to the joint space velocities. The Jacobian matrix for the U-shape fixedbase manipulators is mentioned in Table 1. Jacobian matrix dictates the singularity associated with any manipulator within the given workspace region. The singular positions represent $\|J\|=0[36,46]$. Kinematic isotropy also dictates the overall performance of the manipulators. The higher the kinematic isotropy, the larger is the associated workspace and vice versa. Mohanta et al. [46] have presented the kinematic isotropies of all the 18 PPMs and their effect on the associated overall workspace performance. Singh et al. [M] have also presented the overall workspace associated with the PPMs with varying shape of the fixed base.

\section{U-shape base 3-DOF planar parallel manipulator with SMART linear actuator}

The family of U-shape base PPMs varies in configuration based on the location of active prismatic, passive prismatic and passive revolute joints. Each manipulator has three limbs-one along $X$-axis and the other two along the $Y$-axis. The limb along $X$-axis is referred to as limb-1, the left limb along $Y$-axis is referred as limb-2, and the right limb along $\mathrm{Y}$-axis is referred as limb-3. Each limb consists of two nitinol (NiTi) springs for bidirectional actuation and serves as an active prismatic joint or the joint space displacement $\left(r_{1}, r_{2}\right.$ and $\left.r_{3}\right)$. As discussed, eighteen unique manipulators can be developed by configuring the limbs with $\underline{P R P}, \underline{P} P R$ and $\underline{P} R R$.

To explain it in a better way, the manipulator $C 9$ with its three limbs is depicted in Fig. 4. Here, the combination of limb used is $\underline{P} R P+\underline{P} P R+\underline{P} R R$. The limb- 1 of this manipulator is configured as $P R P$ in which the first $P$ represents the active translational joint actuated by SMA spring and also it has the ability to rotate passively at the joint (7) as shown in Fig. 4. Another link connected with the end-effector and passing through joint (7) serves as a passive translational or prismatic joint.

The limb-2 of this manipulator is configured as PPR, in which the first $P$ represents an active translational joint (8). Another link also translates about the point (8) along $X$-axis which further connects with the end-effector with the passive revolute joint.

The limb-3 of this manipulator has been configured as $P R R$ in which the first $P$ represents active translational joint (9) similar to leg-1 and leg- 2 actuated by SMA springs. Another link is connected to the active translational joint at (9) by the passive revolute joint on one end. The other end is connected to the end-effector with the help of another passive revolute joint. Similarly, all the eighteen 


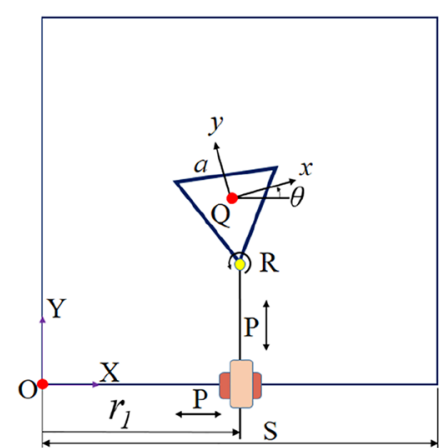

$r_{1}=x+\frac{2 h}{3} \sin \theta$

(a)

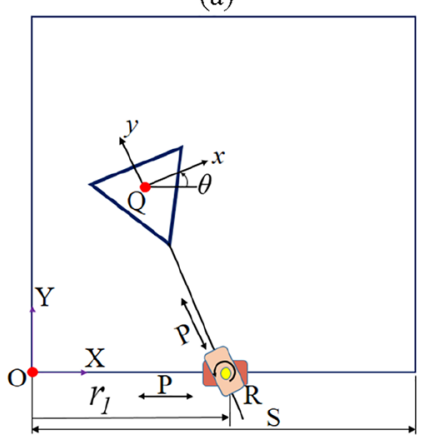

$r_{1}=x+y \tan \theta$

(d)

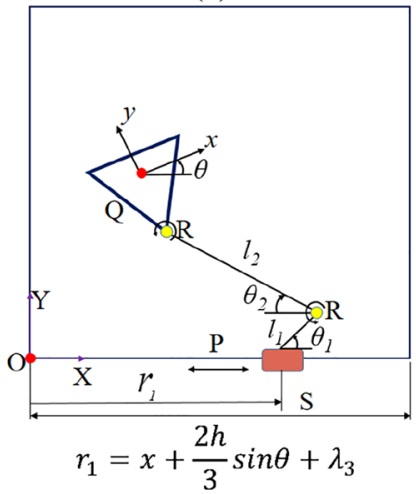

(g)

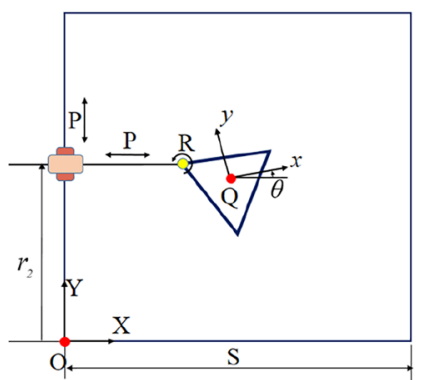

$r_{2}=y+\frac{h}{3} \cos \theta-\frac{a}{2} \sin \theta$

(b)

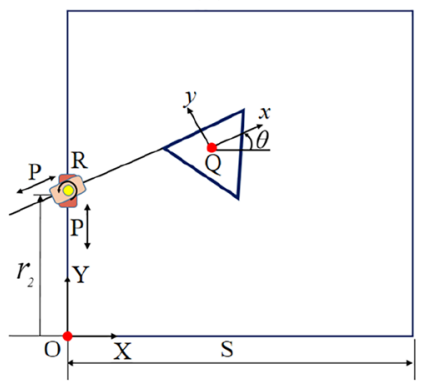

$r_{2}=y+\frac{2 h}{3} \sin \left(30^{\circ}-\theta\right)-\lambda_{1}$

(e)

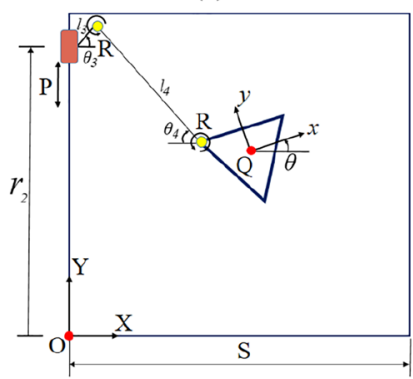

$r_{2}=x+\frac{2 h}{3} \sin \left(30^{0}-\theta\right)+\lambda_{4}$

(h)

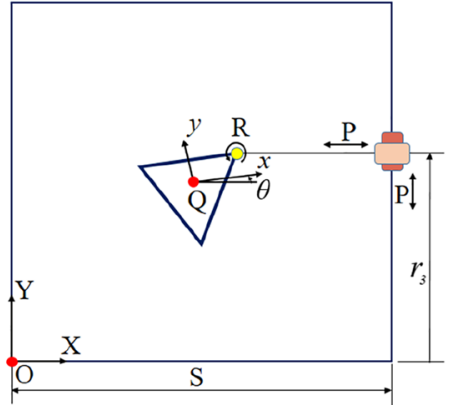

$r_{3}=y+\frac{h}{3} \cos \theta+\frac{a}{2} \sin \theta$

(c)

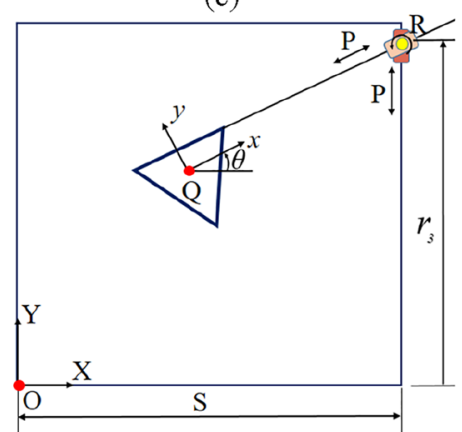

$r_{3}=y+\frac{2 h}{3} \sin \left(30^{\circ}+\theta\right)+\lambda_{2}$

(f)

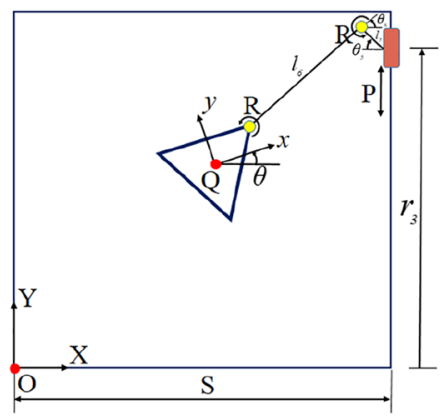

$r_{3}=y+\frac{2 h}{3} \sin \left(30^{0}+\theta\right)+\lambda_{5}$

(i)

where, $\quad \lambda_{1}=\tan \theta\left(x-\frac{2 h}{3} \cos \left(30^{\circ}-\theta\right)\right)$,

$\lambda_{2}=\tan \theta\left(s-x-\frac{2 h}{3} \cos \left(30^{\circ}+\theta\right)\right)$,

$\lambda_{3}=l_{2} \cos \theta_{2}-l_{1} \cos \theta_{1}, \quad \theta_{2}=\sin ^{-1}\left(\frac{y-\frac{2 h}{3} \cos \theta-l_{1} \sin \theta_{1}}{l_{2}}\right)$

$\lambda_{4}=l_{4} \cos \theta_{4}-l_{3} \cos \theta_{3}, \quad \theta_{4}=\cos ^{-1}\left(\frac{x-\frac{2 h}{3} \cos \left(30^{\circ}-\theta\right)-l_{3} \cos \theta_{3}}{l_{4}}\right)$

$\lambda_{5}=l_{6} \cos \theta_{6}-l_{5} \cos \theta_{5}, \quad \theta_{6}=\cos ^{-1}\left(\frac{(s-x)-\frac{2 h}{3} \cos \left(30^{\circ}+\theta\right)-l_{5} \cos \theta_{5}}{l_{6}}\right)$

Fig. 3 Frame diagrams of the family of U-shape fixed-base planar parallel manipulators

manipulators can be obtained by assembling the three limbs with $\underline{P R P}$ or $\underline{P P R}$ or $\underline{P R R}$. The presence of two nitinol SMA springs at each of the limbs (if implemented as shown in Fig. 4) leads to bidirectional translational motion along its axis.

The regulated DC current is supplied to only one spring in the first $\underline{P}$ joint (developed using SMA spring) of each 
Table 1 Jacobian matrix $(\mathrm{J})$ of the family of U-shape fixed-base planar parallel manipulators $\left[\begin{array}{lll}1 & 0 & \frac{2 h}{3} \cos \theta \\ 0 & 1 & \lambda_{15} \\ 0 & 1 & \lambda_{14}\end{array}\right]$

(a) Configuration $1(\mathrm{C} 1)$

$\left[\begin{array}{ccc}1 & 0 & \frac{2 h}{3} \cos \theta \\ -\tan \theta & 1 & \lambda_{12} \\ -\tan \theta & 1 & \lambda_{8}\end{array}\right]$

(d) Configuration 4 (C4)

$\left[\begin{array}{ccc}1 & \tan \theta & y \sec ^{2} \theta \\ 0 & 1 & \lambda_{15} \\ 0 & 1 & \lambda_{14}\end{array}\right]$

(g) Configuration 7 (C7)

$\left[\begin{array}{ccc}1 & \tan \theta & y \sec ^{2} \theta \\ -\tan \theta & 1 & \lambda_{12} \\ -\tan \theta & 1 & \lambda_{8}\end{array}\right]$

(j) Configuration 10 (C10)

$\left[\begin{array}{ccc}1 & -\lambda_{14} & \lambda_{16} \\ 0 & 1 & \lambda_{15} \\ 0 & 1 & \lambda_{14}\end{array}\right]$

(m) Configuration 13 (C13)

$\left[\begin{array}{ccc}1 & -\lambda_{14} & \lambda_{16} \\ -\lambda_{13} & 1 & -\lambda_{10}-\lambda_{11} \lambda_{13} \\ 0 & 1 & \lambda_{14}\end{array}\right]$

(p) Configuration 16 (C16) $\left[\begin{array}{ccc}1 & 0 & \frac{2 h}{3} \cos \theta \\ 0 & 1 & \lambda_{15} \\ -\tan \theta & 1 & \lambda_{8}\end{array}\right]$

(b) Configuration 2 (C2)

$\left[\begin{array}{ccc}1 & 0 & \frac{2 h}{3} \cos \theta \\ -\tan \theta & 1 & \lambda_{12} \\ \lambda_{9} & 1 & \lambda_{6}-\lambda_{7} \lambda_{9}\end{array}\right]$

(e) Configuration 5 (C5)

$\left[\begin{array}{ccc}1 & \tan \theta & y \sec ^{2} \theta \\ 0 & 1 & \lambda_{15} \\ -\tan \theta & 1 & \lambda_{8}\end{array}\right]$

(h) Configuration 8 (C8)

$\left[\begin{array}{ccc}1 & \tan \theta & y \sec ^{2} \theta \\ -\tan \theta & 1 & \lambda_{12} \\ \lambda_{9} & 1 & \lambda_{6}-\lambda_{7} \lambda_{9}\end{array}\right]$

(k) Configuration 11 (C11)

$\left[\begin{array}{ccc}1 & -\lambda_{14} & \lambda_{16} \\ 0 & 1 & \lambda_{15} \\ -\tan \theta & 1 & \lambda_{8}\end{array}\right]$

(n) Configuration 14 (C14)

$\left[\begin{array}{ccc}1 & -\lambda_{14} & \lambda_{16} \\ -\lambda_{13} & 1 & -\lambda_{10}-\lambda_{11} \lambda_{13} \\ -\tan \theta & 1 & \lambda_{8}\end{array}\right]$

(q) Configuration 17 (C17)

(r) Configuration 18 (C18)

$\left[\begin{array}{ccc}1 & 0 & \frac{2 h}{3} \cos \theta \\ 0 & 1 & \lambda_{15} \\ \lambda_{9} & 1 & \lambda_{6}-\lambda_{7} \lambda_{9}\end{array}\right]$

(c) Configuration 3 (C3)

$\left[\begin{array}{ccc}1 & 0 & \frac{2 h}{3} \cos \theta \\ -\lambda_{13} & 1 & -\lambda_{10}-\lambda_{11} \lambda_{13} \\ \lambda_{9} & 1 & \lambda_{6}-\lambda_{7} \lambda_{9}\end{array}\right]$

(f) Configuration 6 (C6)

$\left[\begin{array}{ccc}1 & \tan \theta & y \sec ^{2} \theta \\ 0 & 1 & \lambda_{15} \\ \lambda_{9} & 1 & \lambda_{6}-\lambda_{7} \lambda_{9}\end{array}\right]$

(i) Configuration 9 (C9)

(I) Configuration 12 (C12)

$\left[\begin{array}{ccc}1 & -\lambda_{14} & \lambda_{16} \\ -\tan \theta & 1 & \lambda_{12} \\ -\tan \theta & 1 & \lambda_{8}\end{array}\right]$

(o) Configuration 15 (C15) $\left[\begin{array}{ccc}1 & \tan \theta & y \sec ^{2} \theta \\ -\lambda_{13} & 1 & -\lambda_{10}-\lambda_{11} \lambda_{13} \\ \lambda_{9} & 1 & \lambda_{6}-\lambda_{7} \lambda_{9}\end{array}\right]$

$\left[\begin{array}{ccc}1 & -\lambda_{14} & \lambda_{16} \\ -\lambda_{13} & 1 & -\lambda_{10}-\lambda_{11} \lambda_{13} \\ \lambda_{9} & 1 & -\lambda_{6}-\lambda_{7} \lambda_{9}\end{array}\right]$

where

$$
\begin{array}{ll}
\lambda_{6}=\frac{2 h}{3} \cos \left(30^{\circ}+\theta\right) & \lambda_{7}=\frac{2 h}{3} \sin \left(30^{\circ}+\theta\right) \\
\lambda_{8}=\lambda_{6}+\lambda_{7} \tan \theta+\frac{\sec ^{2} \theta}{\tan \theta} \lambda_{3} & \lambda_{9}=\frac{\sin \theta_{6}}{\sqrt{l_{6}^{2}-\sin ^{2} \theta_{6}}} \\
\lambda_{10}=\frac{2 h}{3} \cos \left(30^{\circ}-\theta\right) & \lambda_{11}=\frac{2 h}{3} \sin \left(30^{\circ}-\theta\right) \\
\lambda_{12}=-\lambda_{10}+\lambda_{11} \tan \theta-\frac{\sec ^{2} \theta}{\tan \theta} \lambda_{2} & \lambda_{13}=\frac{\sin \theta_{4}}{\sqrt{l_{4}^{2}-\sin ^{2} \theta_{4}}} \\
\lambda_{14}=-\frac{h}{3} \sin \theta+\frac{a}{2} \cos \theta & \lambda_{15}=-\frac{h}{3} \sin \theta-\frac{a}{2} \cos \theta \\
\lambda_{16}=\frac{2 h}{3} \cos \theta-\lambda_{14} \frac{2 h}{3} \sin \theta &
\end{array}
$$

limb, and the corresponding spring starts contracting which ceases after some time. This results in the elongation of the other spring connected in series in the same leg. Ultimately, the position of the connector $(7,8,9$ as shown in Fig. 4) of the two springs or active input translational joints as depicted in Fig. 4 varies. This, thereby, leads to variation in the pose of the end-effector.

\section{Experimental procedure}

\subsection{Material selection and specification}

The linear actuator considered for the active translation joint of the manipulator is a one-way nitinol SMA spring of $0.75 \mathrm{~mm}$ wire diameter with 19 helix windings. The NiTi SMA spring can contract maximum up to $29 \mathrm{~mm}$ when thermally induced under no external load. Under

Fig. 4 PRP-P्PR-PRR manipulator (C9) 
Table 2 Properties of nitinol SMA [58]

\begin{tabular}{ll}
\hline Property & Value \\
\hline Density & $6.45 \mathrm{~g} / \mathrm{cm}^{3}$ \\
Young's modulus & $70 \mathrm{GPa}$ \\
Poisson's ratio & 0.33 \\
Tensile yield strength & $559 \mathrm{MPa}$ \\
Compressive yield strength & $560 \mathrm{MPa}$ \\
Tensile ultimate strength & $960 \mathrm{MPa}$ \\
Compressive ultimate strength & $960 \mathrm{MPa}$ \\
\hline
\end{tabular}

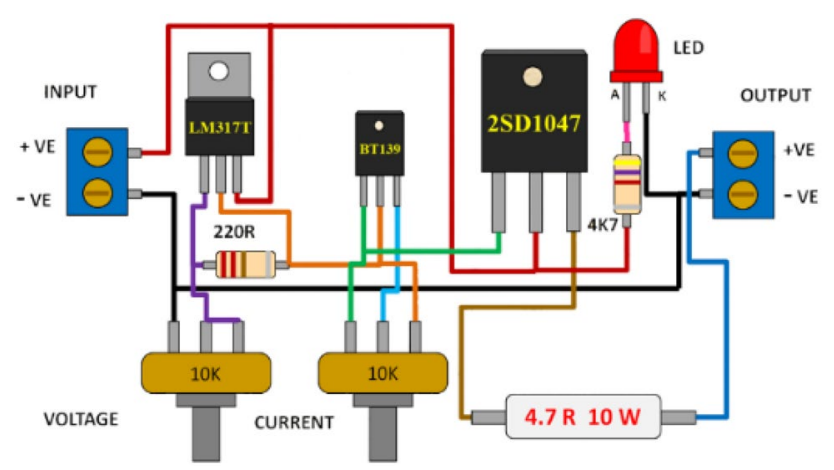

Fig. 5 Circuit diagram of variable DC power supply

external load, the spring can be elongated up to $140 \mathrm{~mm}$. These SMA springs can also be used in series for longer distances and also in parallel for higher force capability. The various physical properties of nitinol are presented in Table 2 [58]. A single spring, under no load condition, activates instantly $(<1 \mathrm{~s})$ for current, $I \geq 2 \mathrm{~A}$. For current under $700 \mathrm{~mA}<I<2 \mathrm{~A}$, the activation time for the nitinol spring ranges from 1 to $3 \mathrm{~s}$. The springs when supplied a direct current of less than $700 \mathrm{~mA}$ requires larger activation time which is greater than $3 \mathrm{~s}$.

\subsection{DC power supply}

In order to actuate the nitinol springs, there is a need to elevate its temperature to the austenite region of prestretched nitinol which leads to phase transformation. The temperature of the SMA springs is raised by passing current through it using a variable DC power supply. The circuit diagram for the developed variable DC power supply is depicted in Fig. 5. The minimum current deviation obtained by the prototype is $10 \mathrm{~mA}$. Supply of electrical current through the nitinol spring increases its temperature due to its electrical resistance, also known as Joule heating, which results in phase transition and change in size of the pre-stretched nitinol spring.
Table 3 FDM process parameter values

\begin{tabular}{ll}
\hline Process parameters & Value \\
\hline Raster width & $0.016 \mathrm{~mm}$ \\
Raster angle & $0^{0}$ \\
Built material tool tip & $\mathrm{T} 16$ \\
Support material tool tip & $\mathrm{T} 12$ \\
Air gap & $0 \mathrm{~mm}$ \\
\hline
\end{tabular}

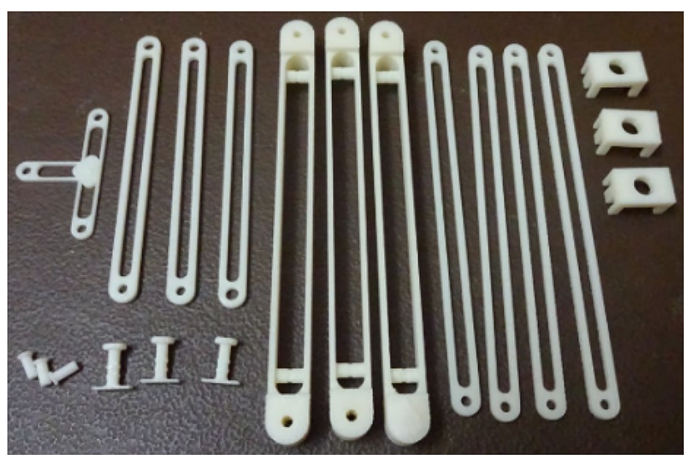

Fig. 6 RPT 3D part models printed using Stratasys FDM 360mc

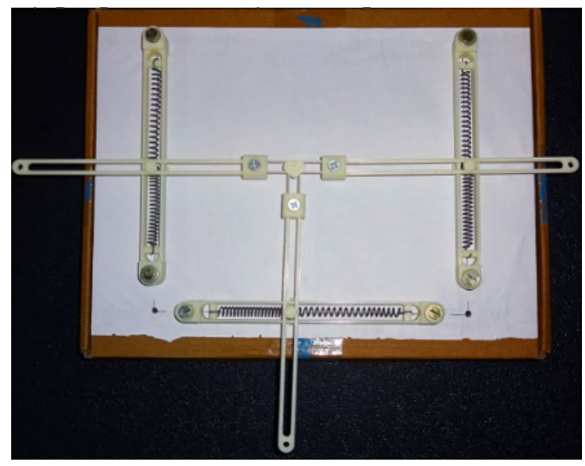

Fig. 7 Assembled C10 configured PPM

\subsection{Development of the prototype}

Rapid prototyping is employed for the rapid fabrication of 3D CAD part models by fused deposition modelling (FDM), an additive manufacturing technology. Acrylonitrile butadiene styrene-M30 (ABS), a thermoplastic material by Stratasys, is used as the part build material. The support material used is SR-30 water-soluble support by Stratasys. The various process parameters used in the FDM process for 3D printing of various parts are mentioned in Table 3.

The CAD model was printed using the Stratasys FDM $360 \mathrm{mc}$ machine, and the various 3D printed parts are depicted in Fig. 6. The components shown in Fig. 6 have been used to make the assembly of the $\mathrm{C} 10$ configured 


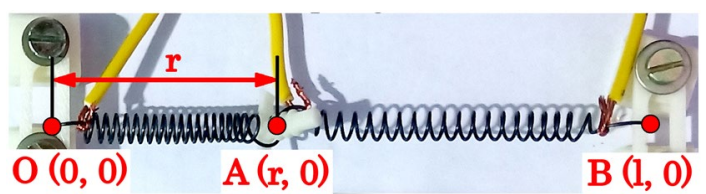

Fig. 8 Nitinol SMA springs arranged in series

PPM, as shown in Fig. 7. Also, other manipulators can be obtained by proper assembly of the parts.

\subsection{Experimental model of a limb with two SMA springs}

To evaluate the behaviour of SMA springs connected in series, a model, depicted in Fig. 8, has been developed to mitigate the design of a limb (or leg) of the manipulator. One end of first spring is fixed at the Origin $(0,0)$ and one end of the other spring is fixed at $\mathrm{B}(I, 0)$, where $I=129 \mathrm{~mm}$. The other ends of the springs are together at the point $\mathrm{A}(r, 0)$ with the help of a pin made of ABS plastic. In this configuration, when direct current is supplied to any of the spring, the other spring reacts and opposes the retraction of the active SMA spring. Due to the presence of opposing force, the SMA stops retracting (under current supply), when it reaches a length of approximately $20 \mathrm{~mm}$ (under $1 \mathrm{~mA}<1<2 \mathrm{~mA}$ ). The activation response of the nitinol spring, under this configuration, ranges from 3 to $7 \mathrm{~s}$ for the direct current ranging from 1 to $2 \mathrm{~mA}$. Initially, the right spring is contracted to get the desired position of $A$ (at $t=0 \mathrm{~s}$ ). Once the position is reached, $1220 \mathrm{~mA}$ of direct current was supplied to the left spring for exactly $100 \mathrm{~s}$ and the retraced distance was measured as presented in Table 4. The same experiment was carried out for 5 different current values with 5 repetitions as presented in the table. The table dictates that the retraction length decreases with the decrease in current supply. Also, it is evident that the performance and repeatability of the SMA-based actuator is quite high.

\subsection{Experimental Set-up for the Workspace Analysis}

In order to perform the experiment to observe the workspace of the 3-DOF U-shape base PPMs using SMART
Table 4 Retraction length of SMA spring (in series) at varied direct current

\begin{tabular}{|c|c|c|c|c|}
\hline Current (mA) & $\begin{array}{l}\text { Initial length } \\
(\mathrm{mm})\end{array}$ & $\begin{array}{l}\text { Final length } \\
(\mathrm{mm})\end{array}$ & $\begin{array}{l}\text { Retraction length } \\
(\mathrm{mm})\end{array}$ & $\begin{array}{l}\text { Mean retraction length } \\
\text { with standard deviation } \\
(\mathrm{mm})\end{array}$ \\
\hline \multirow[t]{5}{*}{1220} & 74.20 & 41.23 & 32.97 & \multirow[t]{5}{*}{$32.94 \pm 0.027$} \\
\hline & 74.20 & 41.27 & 32.93 & \\
\hline & 74.20 & 41.26 & 32.94 & \\
\hline & 74.20 & 41.24 & 32.96 & \\
\hline & 74.20 & 41.30 & 32.90 & \\
\hline \multirow[t]{5}{*}{1160} & 75.50 & 43.91 & 31.59 & \multirow[t]{5}{*}{$31.60 \pm 0.018$} \\
\hline & 75.50 & 43.88 & 31.62 & \\
\hline & 75.50 & 43.93 & 31.57 & \\
\hline & 75.50 & 43.90 & 31.60 & \\
\hline & 75.50 & 43.90 & 31.60 & \\
\hline \multirow[t]{5}{*}{1130} & 73.80 & 45.32 & 28.48 & \multirow[t]{5}{*}{$28.50 \pm 0.024$} \\
\hline & 73.80 & 45.30 & 28.50 & \\
\hline & 73.80 & 45.30 & 28.50 & \\
\hline & 73.80 & 45.26 & 28.54 & \\
\hline & 73.80 & 45.32 & 28.48 & \\
\hline \multirow[t]{5}{*}{1120} & 84.00 & 66.78 & 17.22 & \multirow[t]{5}{*}{$17.19 \pm 0.019$} \\
\hline & 84.00 & 66.81 & 17.19 & \\
\hline & 84.00 & 66.83 & 17.17 & \\
\hline & 84.00 & 66.80 & 17.20 & \\
\hline & 84.00 & 66.82 & 17.18 & \\
\hline \multirow[t]{5}{*}{1060} & 73.00 & 63.21 & 9.79 & \multirow[t]{5}{*}{$9.80 \pm 0.012$} \\
\hline & 73.00 & 63.18 & 9.82 & \\
\hline & 73.00 & 63.21 & 9.79 & \\
\hline & 73.00 & 63.20 & 9.80 & \\
\hline & 73.00 & 63.20 & 9.80 & \\
\hline
\end{tabular}


Table 5 Experimental set-up units

\begin{tabular}{ll}
\hline SI. No. & Experimental set-up units \\
\hline 1 & Extension board \\
2 & AC/DC adapter \\
3 & Variable DC power supply \\
4 & Multimeter \\
5 & Breadboard \\
6 & Planar parallel manipulator \\
7 & Digital camera with tripod \\
\hline
\end{tabular}

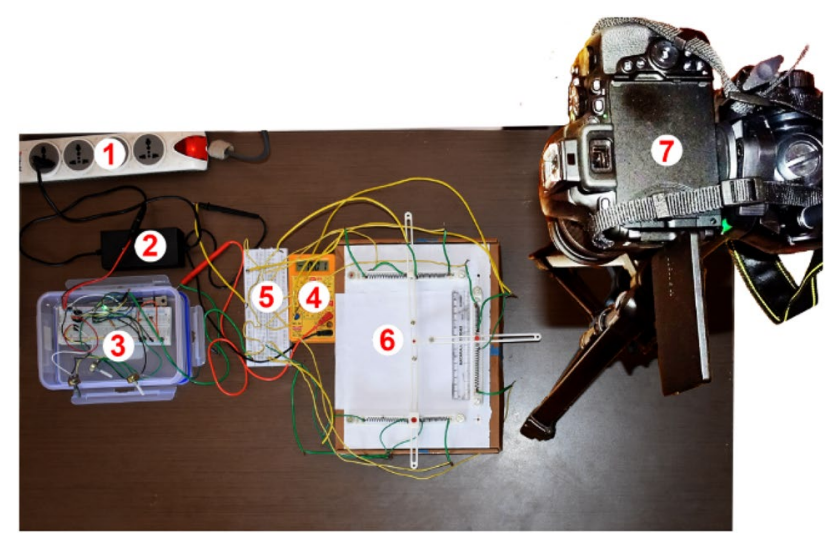

Fig. 9 Experimental set-up

linear actuators, an experimental set-up has been developed. The experimental set-up includes various units, as mentioned in Table 5. The set-up is also depicted in Fig. 9.

In the experimental set-up, the AC/DC adapter (2) receives $A C$ from the extension board (1) and converted the DC serves as input to the variable DC power supply (3). The current is regulated with the help of a potentiometer attached to the variable DC power supply. The regulated $D C$ is monitored using the multimeter (4). The current is then supplied to the SMART linear actuator of the PPM (6) through the breadboard. The breadboard (5) helps in directing the regulated current to the SMA springs in the manipulator limbs in various combinations. The Digital Camera (Nikon D5600) is mounted on a tripod (7) to track the pose of the end-effector of the manipulator.

\section{Workspace analysis}

\subsection{Workspace analysis of CAD models}

The assembled CAD models of all the 18 manipulators have been used to determine the associated workspace. As the experiment resulted in $29 \mathrm{~mm}$ of total contraction for a single spring under no external load condition, the same has been incorporated in the CAD models. The maximum contraction of NiTi SMA springs associated at each of the three limbs has been made limited to $29 \mathrm{~mm}$. The active prismatic joints are then allowed to translate on consideration of physical dynamics. The pose of the manipulator's end-effector is allowed to vary in various combinations of its input translational joints. The movement of active translational joint $r_{1}$ along positive $X$-axis direction is considered as forward movement $(F)$ and along negative $X$-axis is considered as backward (B) movement. Similarly, the movement of active translational joints $r_{2}$ and $r_{3}$ along positive $\mathrm{Y}$-axis direction is considered as forward movement (F) and along negative $Y$-axis is considered as backward (B) movement. Hence, seven different combinations of input translational joints have been considered for workspace analysis, as tabulated in Table 6. Again, these seven combinations have further been divided into various combinations based on the actuation direction ( $F$ or $B$ ) of the input translational joints. The workspace so obtained based on maximum NiTi SMA spring contraction $(29 \mathrm{~mm})$ is referred to be the "Ideal Workspace" of the manipulators. And the condition of maximum contraction-29 mm-is referred as "Ideal Condition".

Also, the experiment of two NiTi SMA springs when connected in series showed that the maximum contraction practically possible is approximately $40 \mathrm{~mm}$ at $1200 \mathrm{~mA}$ of current supply. Hence, it is necessary to identify the workspace based on the feasible condition that the SMA springs can shrink up to $\sim 40 \mathrm{~mm}$. This condition of $40 \mathrm{~mm}$ as the maximum contraction is referred to as "Feasible Condition", and the workspace so obtained is termed as "Feasible Workspace".

The CAD model analysis is repeated again for the family of manipulators discussed here. Two sets of ideal and feasible workspace analyses have been conducted for each manipulator, and the pose of the end-effector was obtained. Table 6 shows the positions of the end-effector of the C1 manipulator under varied conditions of SMA spring actuation. Similar sets of data were obtained for the rest of the manipulators as well. Based on the obtained data, the total stroke length for the end-effector is calculated and is tabulated in Table 7. $\left(Q_{x}, Q_{y}\right)$ in Table 6 represents the position of the end-effector in the Cartesian coordinate system.

\subsection{Comparison study between ideal and feasible workspace}

The workspace area associated with the family of manipulators is consolidated in Table 8 based on the data from Table 7. Table 8 indicates the consolidated displacements of the end-effector along both the axes. This table also indicates the loss in the workspace and the loss in 
Table 6 End-effector position of C1 manipulator under ideal and feasible conditions

\begin{tabular}{|c|c|c|c|c|c|c|c|c|c|}
\hline \multirow{4}{*}{$\begin{array}{l}\text { SMA Actuators } \\
\text { (conditions) }\end{array}$} & \multirow{4}{*}{$\begin{array}{l}\text { Direction of } \\
\text { spring actuation }\end{array}$} & \multicolumn{8}{|c|}{ Position of the end-effector (mm) } \\
\hline & & \multicolumn{4}{|c|}{ Ideal condition } & \multicolumn{4}{|c|}{ Feasible condition } \\
\hline & & \multicolumn{2}{|l|}{ Set 1} & \multicolumn{2}{|l|}{ Set 2} & \multicolumn{2}{|l|}{ Set 1} & \multicolumn{2}{|l|}{ Set 2} \\
\hline & & $Q_{x}$ & $\mathrm{Q}_{\mathrm{y}}$ & $Q_{x}$ & $Q_{y}$ & $Q_{x}$ & $\mathrm{Q}_{\mathrm{y}}$ & $Q_{x}$ & $\mathrm{Q}_{\mathrm{y}}$ \\
\hline \multirow[t]{3}{*}{$r_{1}$} & Initial position & 75.500 & 105.500 & 125.500 & 95.500 & 120.500 & 100.500 & 115.500 & 95.500 \\
\hline & $r_{1}: F$ & 135.750 & 105.500 & 155.750 & 95.500 & 147.000 & 100.500 & 132.000 & 95.500 \\
\hline & $r_{1}: B$ & 58.250 & 105.500 & 78.250 & 95.500 & 97.000 & 100.500 & 82.000 & 95.500 \\
\hline \multirow[t]{3}{*}{$r_{2}$} & Initial position & 58.250 & 105.500 & 78.250 & 95.500 & 97.000 & 100.500 & 82.000 & 95.500 \\
\hline & $r_{2}: F$ & 78.380 & 125.630 & 88.250 & 105.500 & 100.250 & 103.750 & 95.250 & 108.750 \\
\hline & $r_{2}: B$ & 44.480 & 91.730 & 88.250 & 105.500 & 75.250 & 78.750 & 70.250 & 83.750 \\
\hline \multirow[t]{3}{*}{$r_{3}$} & Initial position & 44.480 & 91.730 & 88.250 & 105.500 & 75.250 & 78.750 & 70.250 & 83.750 \\
\hline & $r_{3}: F$ & 44.480 & 91.730 & 58.120 & 135.620 & 53.240 & 100.760 & 53.240 & 100.760 \\
\hline & $r_{3}: B$ & 68.110 & 68.110 & 88.250 & 105.500 & 77.000 & 77.000 & 77.000 & 77.000 \\
\hline \multirow[t]{3}{*}{$r_{1}$ and $r_{2}$} & Initial position & 68.110 & 68.110 & 88.250 & 105.500 & 77.000 & 77.000 & 77.000 & 77.000 \\
\hline & $r_{1}: F, r_{2}: B$ & 140.750 & 63.250 & 132.120 & 71.880 & 127.000 & 77.000 & 125.000 & 77.000 \\
\hline & $r_{1}: B, r_{2}: F$ & 88.250 & 88.250 & 88.250 & 105.500 & 102.000 & 102.000 & 102.000 & 102.000 \\
\hline \multirow[t]{3}{*}{$r_{1}$ and $r_{3}$} & Initial position & 88.250 & 88.250 & 88.250 & 105.500 & 102.000 & 102.000 & 102.000 & 102.000 \\
\hline & $r_{1}: F, r_{3}: F$ & 120.360 & 120.360 & 135.620 & 135.620 & 113.330 & 113.330 & 125.000 & 125.000 \\
\hline & $r_{1}: B, r_{3}: B$ & 81.610 & 81.610 & 88.250 & 105.500 & 88.330 & 88.330 & 102.000 & 100.000 \\
\hline \multirow[t]{3}{*}{$r_{2}$ and $r_{3}$} & Initial position & 81.610 & 81.610 & 88.250 & 105.500 & 88.330 & 88.330 & 97.270 & 104.730 \\
\hline & $r_{2}: B, r_{3}: F$ & 44.480 & 82.020 & 88.250 & 105.500 & 53.240 & 100.760 & 53.240 & 101.240 \\
\hline & $r_{2}: B, r_{3}: B$ & 63.250 & 63.250 & 63.250 & 63.250 & 77.000 & 77.000 & 77.000 & 77.000 \\
\hline \multirow[t]{7}{*}{$r_{1}, r_{2}$ and $r_{3}$} & Initial position & 63.250 & 63.250 & 63.250 & 63.250 & 77.000 & 77.000 & 77.000 & 77.000 \\
\hline & $r_{1}: F, r_{2}: B, r_{3}: F$ & 115.750 & 88.250 & 115.750 & 88.250 & 102.000 & 102.000 & 100.000 & 102.000 \\
\hline & $r_{1}: B, r_{2}: F, r_{3}: B$ & 88.250 & 88.250 & 88.250 & 88.250 & 102.000 & 102.000 & 102.000 & 102.000 \\
\hline & $r_{1}: F, r_{2}: F, r_{3}: F$ & 140.750 & 140.750 & 140.750 & 140.750 & 127.000 & 127.000 & 125.000 & 125.000 \\
\hline & $r_{1}: B, r_{2}: F, r_{3}: F$ & 63.250 & 140.750 & 63.250 & 140.750 & 77.000 & 127.000 & 77.000 & 125.000 \\
\hline & $r_{1}: B, r_{2}: B, r_{3}: B$ & 63.250 & 63.250 & 63.250 & 63.250 & 77.000 & 77.000 & 77.000 & 77.000 \\
\hline & $r_{1}: F, r_{2}: B, r_{3}: B$ & 140.750 & 63.250 & 140.750 & 63.250 & 127.000 & 77.000 & 125.000 & 77.000 \\
\hline
\end{tabular}

' $F$ ' and ' $B$ ' represent forward and backward actuation, respectively, at the legs of the manipulator

individual displacements along both the axes. The loss resulted is due to the difference in contraction length between the ideal and feasible conditions.

Table 8 clearly indicates that the total workspace area is highest for $\mathrm{C} 5$ under both ideal and feasible conditions. The manipulators $\mathrm{C} 16$ and $\mathrm{C} 17$ have minimum ideal and feasible workspace areas, respectively. Similarly, it can be identified that under feasible condition, the manipulators $\mathrm{C} 13$ and $\mathrm{C} 5$ have the maximum displacements along $\mathrm{X}$ and $\mathrm{Y}$-axes, respectively. Although $\mathrm{C} 5$ has the highest ideal and feasible workspace area, it has the least percentage loss in the workspace area.

Figure 10 clearly illustrates that the ideal workspace area is more as compared to the feasible workspace area. It also clearly illustrates the variation in the workspace area of all the manipulators.
Figure 11 depicts the loss incurred in each manipulator due to the difference in maximum contraction length between the ideal and the feasible condition. The loss incurred is due to the displacements along individual axes, which in turn leads to a reduction in the workspace area of the manipulators. This plot can be used to identify the performance of the manipulators based on the overall loss incurred.

\subsection{Comparison study of end-effector rotation under ideal and feasible conditions}

The maximum angular rotation $(\theta)$ of the end-effector for each of the eighteen unique manipulators was obtained based on the ideal and feasible condition, as mentioned earlier. Table 9 gives the maximum angular rotation data of 
Table 7 Ideal and feasible workspace of all the 18 configured 3-DOF U-shaped base PPMs

\begin{tabular}{|c|c|c|c|c|c|c|c|c|}
\hline \multirow[t]{2}{*}{ SI. No. } & \multirow[t]{2}{*}{ Manipulators } & \multirow[t]{2}{*}{ Parameter } & \multicolumn{3}{|c|}{ Ideal workspace } & \multicolumn{3}{|c|}{ Feasible workspace } \\
\hline & & & Minimum & Maximum & Stroke length & Minimum & Maximum & Stroke length \\
\hline \multirow[t]{2}{*}{1} & $\mathrm{C} 1$ & $\mathrm{Q}_{\mathrm{x}}(\mathrm{mm})$ & 44.48 & 155.75 & 111.27 & 53.24 & 147.00 & 93.76 \\
\hline & & $\mathrm{Q}_{\mathrm{y}}(\mathrm{mm})$ & 63.25 & 140.75 & 77.50 & 77.00 & 127.00 & 50.00 \\
\hline \multirow[t]{2}{*}{2} & $\mathrm{C} 2$ & $\mathrm{Q}_{\mathrm{x}}(\mathrm{mm})$ & 53.07 & 140.75 & 87.68 & 69.47 & 127.77 & 58.30 \\
\hline & & $\mathrm{Q}_{\mathrm{y}}(\mathrm{mm})$ & 63.25 & 140.75 & 77.50 & 77.00 & 127.00 & 50.00 \\
\hline \multirow[t]{2}{*}{3} & $\mathrm{C} 3$ & $\mathrm{Q}_{\mathrm{x}}(\mathrm{mm})$ & 94.00 & 159.52 & 65.52 & 95.13 & 148.70 & 53.57 \\
\hline & & $\mathrm{Q}_{\mathrm{y}}(\mathrm{mm})$ & 38.59 & 159.52 & 120.93 & 58.80 & 114.23 & 55.43 \\
\hline \multirow[t]{2}{*}{4} & $\mathrm{C} 4$ & $\mathrm{Q}_{\mathrm{x}}(\mathrm{mm})$ & 54.37 & 140.75 & 86.38 & 69.16 & 129.84 & 60.68 \\
\hline & & $\mathrm{Q}_{\mathrm{y}}(\mathrm{mm})$ & 63.25 & 140.75 & 77.50 & 75.00 & 124.00 & 49.00 \\
\hline \multirow[t]{2}{*}{5} & $\mathrm{C} 5$ & $\mathrm{Q}_{\mathrm{x}}(\mathrm{mm})$ & 70.64 & 144.67 & 74.03 & 70.51 & 139.33 & 68.82 \\
\hline & & $\mathrm{Q}_{\mathrm{y}}(\mathrm{mm})$ & 28.70 & 167.53 & 138.83 & 31.55 & 166.72 & 135.17 \\
\hline \multirow[t]{2}{*}{6} & C6 & $\mathrm{Q}_{\mathrm{x}}(\mathrm{mm})$ & 96.19 & 110.00 & 13.81 & 96.39 & 108.84 & 12.45 \\
\hline & & $\mathrm{Q}_{\mathrm{y}}(\mathrm{mm})$ & 63.49 & 158.61 & 95.12 & 66.71 & 146.84 & 80.13 \\
\hline \multirow[t]{2}{*}{7} & $\mathrm{C} 7$ & $\mathrm{Q}_{\mathrm{x}}(\mathrm{mm})$ & 54.37 & 140.75 & 86.38 & 71.05 & 130.64 & 59.59 \\
\hline & & $\mathrm{Q}_{\mathrm{y}}(\mathrm{mm})$ & 63.25 & 140.75 & 77.50 & 77.00 & 127.00 & 50.00 \\
\hline \multirow[t]{2}{*}{8} & $\mathrm{C} 8$ & $\mathrm{Q}_{\mathrm{x}}(\mathrm{mm})$ & 42.73 & 153.25 & 110.52 & 53.04 & 150.91 & 97.87 \\
\hline & & $\mathrm{Q}_{\mathrm{y}}(\mathrm{mm})$ & 63.25 & 140.75 & 77.50 & 77.00 & 127.00 & 50.00 \\
\hline \multirow[t]{2}{*}{9} & $\mathrm{C} 9$ & $\mathrm{Q}_{\mathrm{x}}(\mathrm{mm})$ & 94.00 & 166.31 & 72.31 & 94.24 & 158.07 & 63.83 \\
\hline & & $\mathrm{Q}_{\mathrm{y}}(\mathrm{mm})$ & 40.45 & 147.95 & 107.50 & 56.55 & 132.78 & 76.23 \\
\hline \multirow[t]{2}{*}{10} & C10 & $\mathrm{Q}_{\mathrm{x}}(\mathrm{mm})$ & 42.22 & 157.05 & 114.83 & 53.88 & 145.40 & 91.52 \\
\hline & & $\mathrm{Q}_{\mathrm{y}}(\mathrm{mm})$ & 63.25 & 140.75 & 77.50 & 75.00 & 124.00 & 49.00 \\
\hline \multirow[t]{2}{*}{11} & C11 & $\mathrm{Q}_{\mathrm{x}}(\mathrm{mm})$ & 94.01 & 156.04 & 62.03 & 94.06 & 120.92 & 26.86 \\
\hline & & $\mathrm{Q}_{\mathrm{y}}(\mathrm{mm})$ & 29.16 & 163.98 & 134.82 & 46.50 & 146.41 & 99.91 \\
\hline \multirow[t]{2}{*}{12} & $\mathrm{C} 12$ & $\mathrm{Q}_{\mathrm{x}}(\mathrm{mm})$ & 94.48 & 110.00 & 15.52 & 95.18 & 108.82 & 13.64 \\
\hline & & $\mathrm{Q}_{\mathrm{y}}(\mathrm{mm})$ & 50.76 & 164.65 & 113.89 & 51.76 & 94.20 & 42.44 \\
\hline \multirow[t]{2}{*}{13} & C13 & $\mathrm{Q}_{\mathrm{x}}(\mathrm{mm})$ & 36.00 & 168.00 & 132.00 & 36.00 & 168.00 & 132.00 \\
\hline & & $\mathrm{Q}_{\mathrm{y}}(\mathrm{mm})$ & 63.25 & 110.00 & 46.75 & 77.00 & 110.00 & 33.00 \\
\hline \multirow[t]{2}{*}{14} & C14 & $\mathrm{Q}_{\mathrm{x}}(\mathrm{mm})$ & 44.44 & 108.47 & 64.03 & 60.10 & 105.52 & 45.42 \\
\hline & & $\mathrm{Q}_{\mathrm{y}}(\mathrm{mm})$ & 60.88 & 109.76 & 48.88 & 69.03 & 106.65 & 37.62 \\
\hline \multirow[t]{2}{*}{15} & C15 & $\mathrm{Q}_{\mathrm{x}}(\mathrm{mm})$ & 36.00 & 168.00 & 132.00 & 36.33 & 168.00 & 131.67 \\
\hline & & $\mathrm{Q}_{\mathrm{y}}(\mathrm{mm})$ & 63.25 & 110.00 & 46.75 & 77.00 & 109.82 & 32.82 \\
\hline \multirow[t]{2}{*}{16} & C16 & $\mathrm{Q}_{\mathrm{x}}(\mathrm{mm})$ & 94.14 & 110.00 & 15.86 & 98.16 & 105.84 & 7.68 \\
\hline & & $\mathrm{Q}_{\mathrm{y}}(\mathrm{mm})$ & 84.96 & 109.79 & 24.83 & 91.15 & 109.78 & 18.63 \\
\hline \multirow[t]{2}{*}{17} & $\mathrm{C} 17$ & $\mathrm{Q}_{\mathrm{x}}(\mathrm{mm})$ & 90.64 & 110.00 & 19.36 & 100.29 & 109.31 & 9.02 \\
\hline & & $\mathrm{Q}_{\mathrm{y}}(\mathrm{mm})$ & 86.74 & 109.98 & 23.24 & 100.66 & 109.96 & 9.30 \\
\hline \multirow[t]{2}{*}{18} & C18 & $\mathrm{Q}_{\mathrm{x}}(\mathrm{mm})$ & 36.22 & 168.00 & 131.78 & 36.51 & 167.97 & 131.46 \\
\hline & & $\mathrm{Q}_{\mathrm{y}}(\mathrm{mm})$ & 63.25 & 109.87 & 46.62 & 77.00 & 109.81 & 32.81 \\
\hline
\end{tabular}

the end-effector for each of the manipulators. The angular values so mentioned have been obtained by CAD analysis in solid modelling software.

\subsection{Experimental workspace analysis}

Table 8 and Fig. 10 clearly indicate that the top three manipulators based on maximum feasible workspace area are $\mathrm{C} 5, \mathrm{C} 8$ and $\mathrm{C} 9$. Hence, these three manipulators have been considered for further analysis of workspace experimentally by incorporating NiTi SMA springs.
The linear actuation of the manipulators' legs results in a change in position of the end-effector for all the three different selected manipulators. Due to coupled kinematic relations, the end-effector pose varies in the $X Y$ plane. The joint of two springs at each leg plays an important role in coordinating linear actuation to the end-effector.

Experiments were conducted in the in-house fabricated prototypes of the three selected manipulators and the end-effector pose was obtained, as depicted in Figs. 12, 13 and 14 based on various combinations of input 


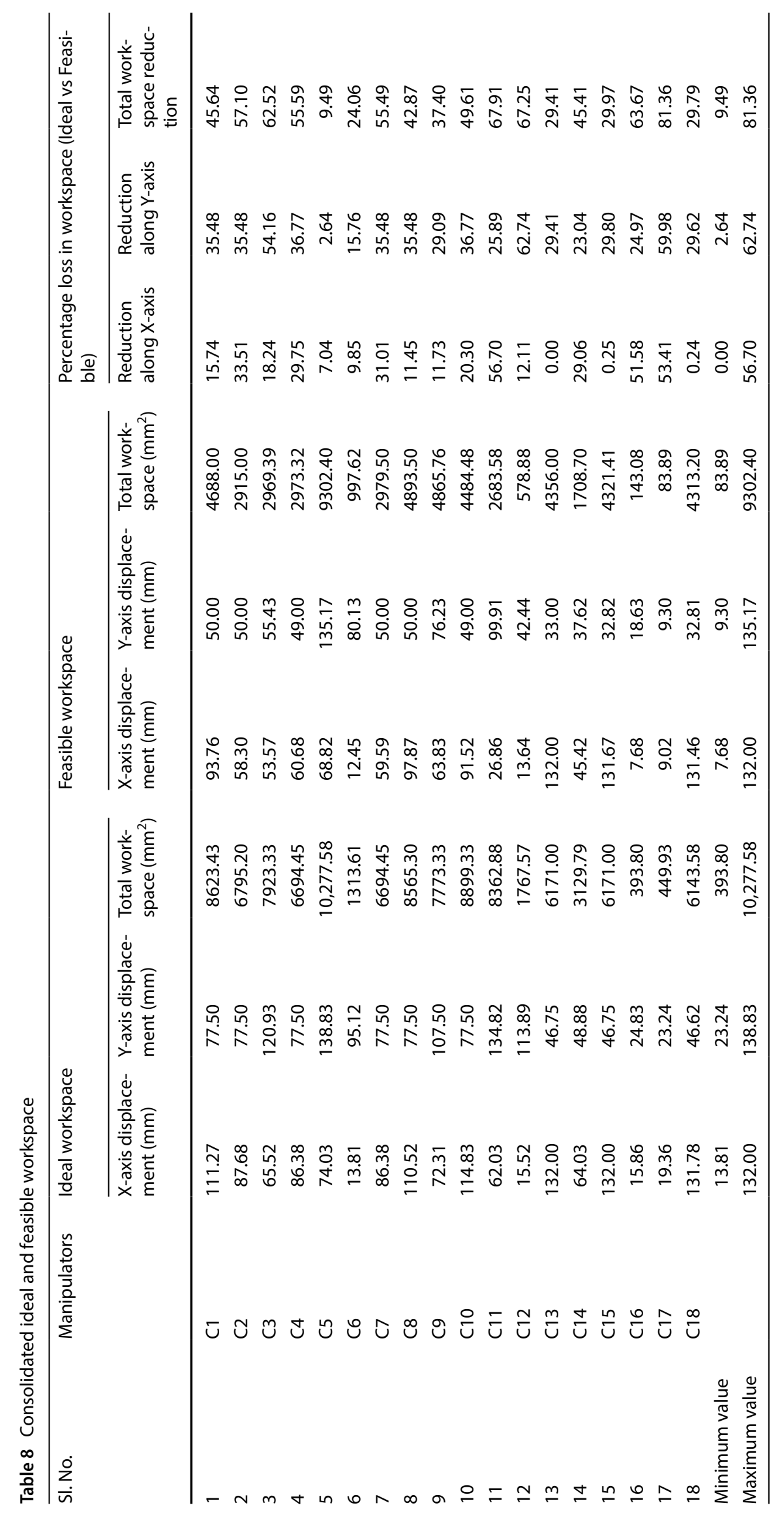




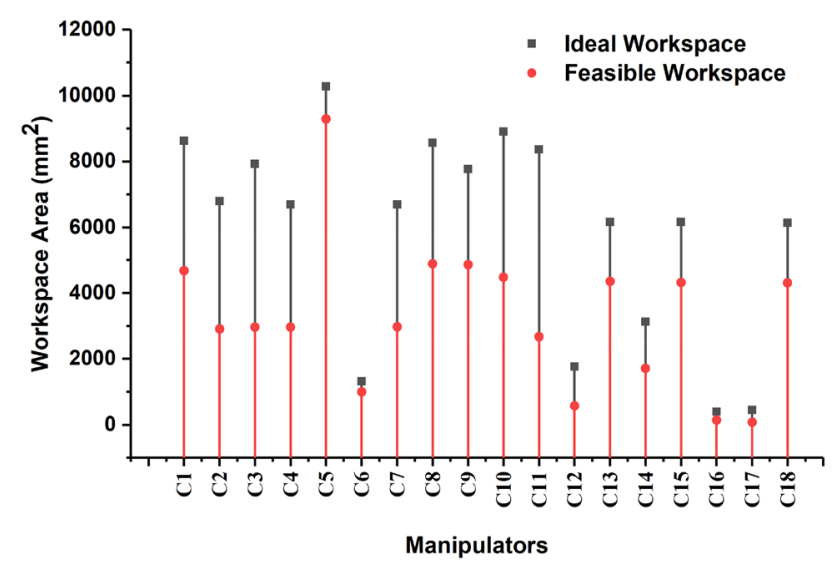

Fig. 10 Ideal and feasible workspace area of manipulators

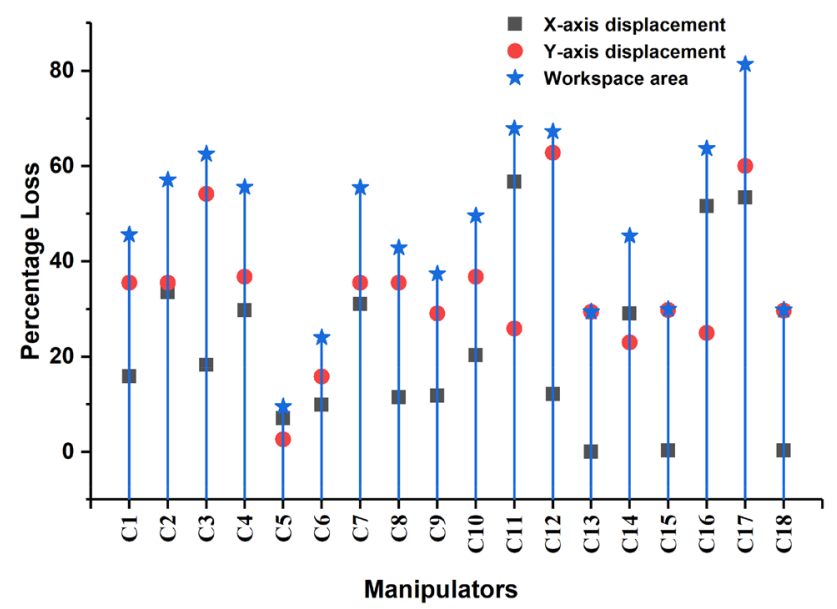

Fig. 11 Percentage loss in workspace

translational units along with the combinations of forward and backward strokes. The experimental data so obtained are presented in Tables 10, 11 and 12.

\subsection{Comparison study between feasible and experimental workspace of $U$-shaped base planar parallel manipulators}

The workspace area associated with each of the three experimented manipulators has been compared with the feasible workspace data in Table 13. The table clearly indicates a further decrease in the workspace area under experiment when compared to the feasible workspace area. As interpreted, the workspace area is highest for the C5 manipulator even after a $60.25 \%$ loss in the workspace area. The $\mathrm{C} 8$ and $\mathrm{C} 5$ manipulators provide the highest displacements along $\mathrm{X}$ - and $\mathrm{Y}$-axes respectively, within the workspace. 


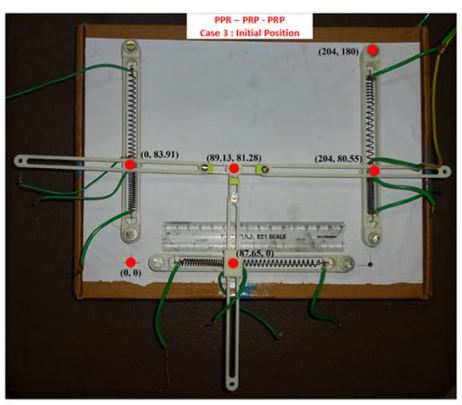

(a) Initial Position

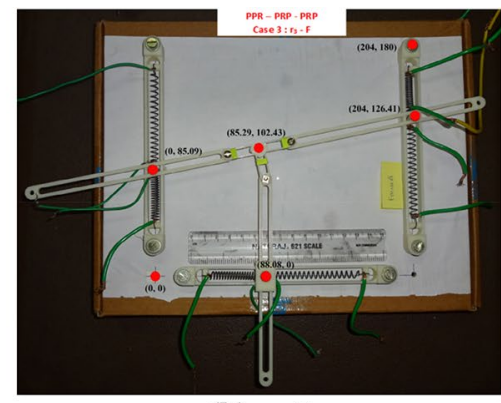

(b) $\mathrm{r}_{3}-\mathrm{F}$

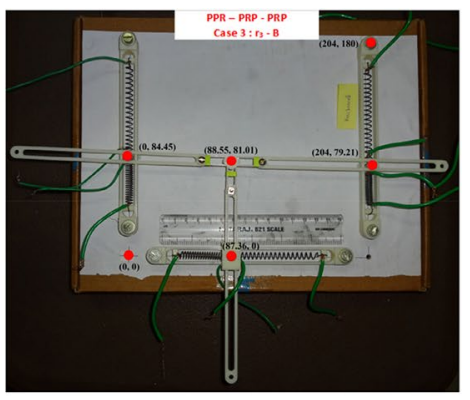

(c) $r_{3}-\mathrm{B}$

Fig. 12 Actuation of SMA springs of C5 manipulator (Condition 3)

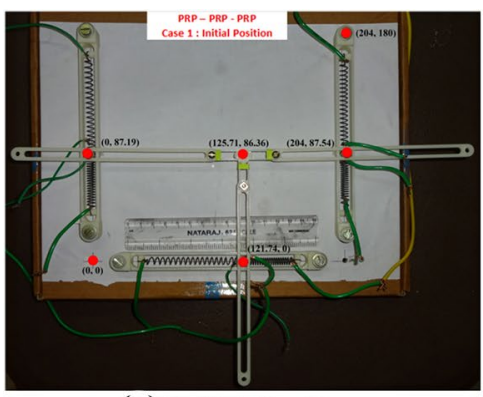

(a) Initial Position

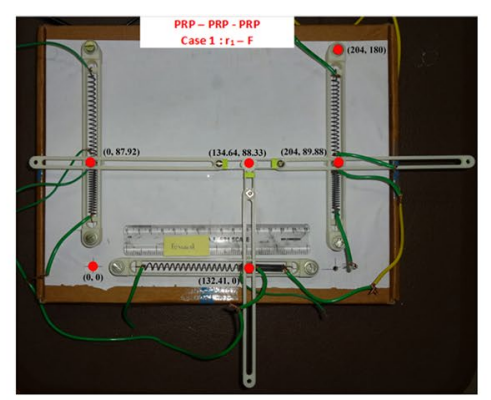

(b) $\mathbf{r}_{1}-\mathrm{F}$

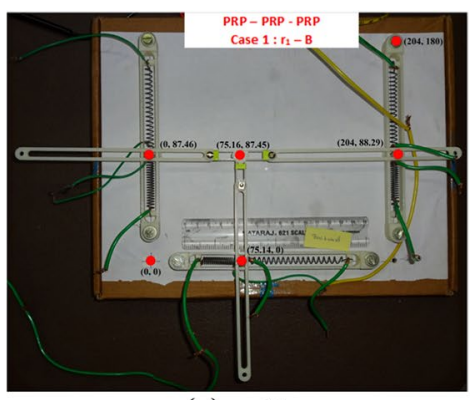

(c) $\mathrm{r}_{1}-\mathrm{B}$

Fig. 13 Actuation of SMA springs of C8 manipulator (Condition 1)

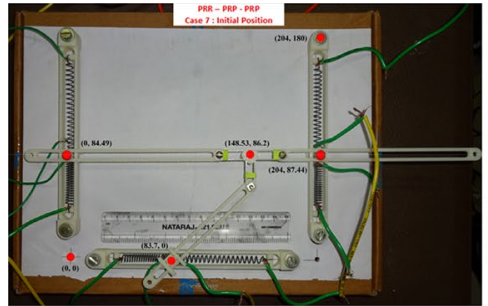

(a) Initial Position

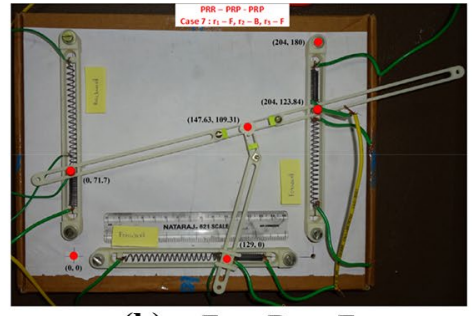

(b) $r_{1}-F, r_{2}-B, r_{3}-F$

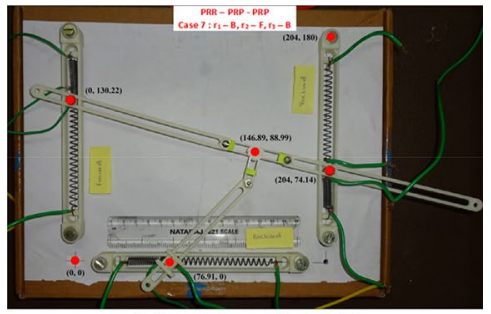

(c) $\mathrm{r}_{1}-\mathrm{B}, \mathrm{r}_{2}-\mathrm{F}, \mathrm{r}_{3}-\mathrm{B}$

Fig. 14 Actuation of SMA springs of C9 manipulator (Condition 7)

The loss in the experimental workspace area as compared to the feasible workspace area is quantitatively mentioned in Table 13. The loss in the workspace results due to various factors, some of which include-(i) singularities and (ii) friction between mobile parts in contact.

\section{(i) Singularities}

Jacobian and the kinematic isotropy are the performance indices of manipulators, as discussed in Sect. 2. Jacobian matrix theoretically dictates the singular positions associated with any manipulator which affects the overall workspace. The kinematic isotropy of various manipulators has already been presented in the literature [46] which dictates the effect of singularity on the reduction of workspace. Figure 15, resembling the C8 manipulator, depicts the position of the manipulator at which singularity exists. It can be seen that Link 2 is parallel to $X$-axis and is fully displaced towards the right. Now, even if the actuator $r_{1}$ tries to actuate in the forward direction (positive $\mathrm{X}$-axis), the end-effector (represented as a red dot) remains still as it loses its degrees of freedom. The end-effector resists the forces and moments due to the forward actuation of $r_{1}$. Also, at the same position of links and joints, even when $r_{3}$ actuates backward (negative $Y$-axis), the end-effec- 
Table 10 Experimental workspace of $\mathrm{C} 5$ manipulator

\begin{tabular}{|c|c|c|c|c|c|c|c|c|c|}
\hline \multirow{3}{*}{$\begin{array}{l}\text { Actuators made of } \\
\text { SMA springs (condi- } \\
\text { tions) }\end{array}$} & \multirow{3}{*}{$\begin{array}{l}\text { Direction of the actuation } \\
\text { during heating of the SMA } \\
\text { springs }\end{array}$} & \multicolumn{8}{|c|}{ Position of the end-effector } \\
\hline & & \multicolumn{2}{|l|}{ Set-1 } & \multicolumn{2}{|l|}{ Set-2 } & \multicolumn{2}{|l|}{ Set-3 } & \multicolumn{2}{|l|}{ Set-4 } \\
\hline & & $\mathrm{Q}_{\mathrm{x}}(\mathrm{mm})$ & $\mathrm{Q}_{\mathrm{y}}(\mathrm{mm})$ & $\mathrm{Q}_{\mathrm{x}}(\mathrm{mm})$ & $\mathrm{Q}_{\mathrm{y}}(\mathrm{mm})$ & $\mathrm{Q}_{\mathrm{x}}(\mathrm{mm})$ & $\mathrm{Q}_{\mathrm{y}}(\mathrm{mm})$ & $\mathrm{Q}_{\mathrm{x}}(\mathrm{mm})$ & $\mathrm{Q}_{\mathrm{y}}(\mathrm{mm})$ \\
\hline \multirow[t]{3}{*}{$r_{1}$} & Initial position & 90.060 & 102.120 & 90.700 & 112.410 & 92.730 & 113.150 & 89.310 & 108.130 \\
\hline & $r_{1}: F$ (Forward direction) & 105.210 & 139.060 & 99.210 & 132.090 & 108.050 & 143.510 & 108.380 & 144.230 \\
\hline & $r_{1}: B$ (Backward direction) & 89.800 & 108.530 & 89.570 & 114.090 & 88.460 & 106.880 & 88.260 & 107.120 \\
\hline \multirow[t]{3}{*}{$r_{2}$} & Initial position & 99.890 & 136.770 & 96.250 & 124.480 & 96.290 & 124.880 & 96.070 & 125.839 \\
\hline & $r_{2}: F$ (Forward direction) & 99.400 & 144.060 & 98.250 & 143.280 & 99.100 & 145.909 & 100.410 & 143.621 \\
\hline & $r_{2}: B$ (Backward direction) & 94.340 & 122.770 & 96.450 & 119.020 & 95.780 & 120.900 & 95.120 & 120.309 \\
\hline \multirow[t]{3}{*}{$r_{3}$} & Initial position & 96.810 & 124.000 & 99.550 & 115.170 & 98.390 & 122.319 & 98.980 & 118.946 \\
\hline & $r_{3}: F$ (Forward direction) & 94.870 & 128.520 & 93.620 & 133.200 & 93.470 & 133.618 & 95.060 & 132.255 \\
\hline & $r_{3}: B$ (Backward direction) & 101.040 & 112.110 & 99.980 & 118.060 & 100.390 & 117.614 & 100.560 & 113.711 \\
\hline \multirow[t]{3}{*}{$r_{1}$ and $r_{2}$} & Initial position & 99.440 & 118.650 & 95.710 & 120.530 & 97.100 & 125.441 & 94.540 & 119.393 \\
\hline & $r_{1}: F$ and $r_{2}: B$ & 109.170 & 131.690 & 108.270 & 133.880 & 112.780 & 136.706 & 108.550 & 135.833 \\
\hline & $r_{1}: B$ and $r_{2}: F$ & 94.340 & 127.170 & 95.570 & 128.550 & 94.490 & 121.194 & 90.830 & 115.122 \\
\hline \multirow[t]{3}{*}{$r_{1}$ and $r_{3}$} & Initial position & 92.090 & 116.500 & 90.960 & 105.730 & 91.360 & 108.322 & 91.320 & 111.812 \\
\hline & $r_{1}: F$ and $r_{3}: F$ & 107.870 & 157.400 & 102.640 & 154.850 & 105.610 & 157.740 & 105.620 & 156.501 \\
\hline & $r_{1}: B$ and $r_{3}: B$ & 88.380 & 101.050 & 88.740 & 98.360 & 89.100 & 97.615 & 87.740 & 107.600 \\
\hline \multirow[t]{3}{*}{$r_{2}$ and $r_{3}$} & Initial position & 89.940 & 118.050 & 91.830 & 87.310 & 91.700 & 86.124 & 91.710 & 86.129 \\
\hline & $r_{2}: B$ and $r_{3}: F$ & 93.630 & 88.370 & 92.920 & 90.070 & 92.450 & 86.547 & 92.240 & 86.310 \\
\hline & $r_{2}: B$ and $r_{3}: B$ & 92.300 & 83.240 & 92.220 & 86.990 & 91.970 & 85.538 & 92.180 & 85.190 \\
\hline \multirow[t]{7}{*}{$r_{1}, r_{2}$ and $r_{3}$} & Initial position & 91.610 & 86.760 & 106.590 & 128.900 & 104.300 & 128.368 & 105.200 & 128.500 \\
\hline & $r_{1}: F, r_{2}: B$ and $r_{3}: F$ & 123.910 & 59.040 & 104.850 & 144.600 & 104.280 & 143.753 & 105.600 & 144.240 \\
\hline & $r_{1}: B, r_{2}: F$ and $r_{3}: B$ & 93.550 & 77.930 & 90.190 & 107.080 & 89.520 & 105.609 & 89.820 & 106.350 \\
\hline & $r_{1}: F, r_{2}: F$ and $r_{3}: F$ & 105.820 & 156.470 & 107.640 & 157.190 & 108.730 & 158.144 & 108.240 & 157.620 \\
\hline & $r_{1}: B, r_{2}: F$ and $r_{3}: F$ & 87.890 & 127.090 & 88.100 & 121.500 & 88.920 & 123.772 & 89.140 & 122.610 \\
\hline & $r_{1}: B, r_{2}: B$ and $r_{3}: B$ & 86.600 & 83.300 & 91.060 & 82.820 & 89.890 & 81.651 & 90.410 & 82.260 \\
\hline & $r_{1}: F, r_{2}: B$ and $r_{3}: B$ & 109.960 & 127.100 & 106.720 & 125.200 & 107.690 & 123.023 & 107.260 & 124.220 \\
\hline
\end{tabular}

tor is unable to change its position. It is because Link 3 is unable to displace any more along the positive $X$ direction. Hence, it represents the presence of singularity. This kind of singularity is known as an inverse kinematic singularity. It reduces the workspace of PPMs to a large extent. Similarly, there exist direct kinematic and combined singularities in various PPMs, which leads to workspace loss.

(ii) Friction between mobile parts in contact.

The fabricated model has various link joints that are in contact with various elements or parts. As the input translational joint actuates, the motion is transferred by the motion of various links and joints connected in between the end-effector and the input translational joints. As there exists relative motion between the links and the joints, the rela- tive force and the relative velocity decrease. Due to the loss in the relative forces and the relative velocity, there exists a loss in the stroke length of the input translational joints and the end-effector along both $\mathrm{X}$ - and $\mathrm{Y}$-axes. This results in a decrease in the overall workspace of the manipulators.

Figures 16, 17 and 18 clearly depicts the different workspace area in the XY plane associated with each of the manipulators.

The plot in Fig. 19 clearly indicates that the $C 5$ manipulator has a wider workspace length along the $\mathrm{Y}$-axes and the C8 manipulator has a wider workspace length along the $X$-axis. All the three manipulators acquire different regions in the $X Y$ plane within the domain of the mobile platform. 
Table 11 Experimental workspace of C8 manipulator

\begin{tabular}{|c|c|c|c|c|c|c|c|c|c|}
\hline \multirow{3}{*}{$\begin{array}{l}\text { Actuators made of } \\
\text { SMA springs (condi- } \\
\text { tions) }\end{array}$} & \multirow{3}{*}{$\begin{array}{l}\text { Direction of the actuation } \\
\text { during heating of the SMA } \\
\text { springs }\end{array}$} & \multicolumn{8}{|c|}{ Position of the end-effector } \\
\hline & & \multicolumn{2}{|l|}{ Set-1 } & \multicolumn{2}{|l|}{ Set-2 } & \multicolumn{2}{|l|}{ Set-3 } & \multicolumn{2}{|l|}{ Set-4 } \\
\hline & & $\mathrm{Q}_{\mathrm{x}}(\mathrm{mm})$ & $\mathrm{Q}_{\mathrm{y}}(\mathrm{mm})$ & $\mathrm{Q}_{\mathrm{x}}(\mathrm{mm})$ & $\mathrm{Q}_{\mathrm{y}}(\mathrm{mm})$ & $\mathrm{Q}_{\mathrm{x}}(\mathrm{mm})$ & $\mathrm{Q}_{\mathrm{y}}(\mathrm{mm})$ & $\mathrm{Q}_{\mathrm{x}}(\mathrm{mm})$ & $\mathrm{Q}_{\mathrm{y}}(\mathrm{mm})$ \\
\hline \multirow[t]{3}{*}{$r_{1}$} & Initial position & 97.300 & 93.303 & 76.530 & 92.926 & 77.140 & 91.636 & 79.360 & 93.055 \\
\hline & $\mathrm{r}_{1}: \mathrm{F}$ (Forward direction) & 112.890 & 94.009 & 114.410 & 93.525 & 109.140 & 93.376 & 110.750 & 93.282 \\
\hline & $r_{1}: B$ (Backward direction) & 75.890 & 93.008 & 76.670 & 91.122 & 78.740 & 92.910 & 83.780 & 91.900 \\
\hline \multirow[t]{3}{*}{$r_{2}$} & Initial position & 86.030 & 93.764 & 82.670 & 91.338 & 84.530 & 91.823 & 86.750 & 91.686 \\
\hline & $r_{2}: F$ (Forward direction) & 100.270 & 116.104 & 103.560 & 117.210 & 110.150 & 114.686 & 107.820 & 114.729 \\
\hline & $r_{2}: B$ (Backward direction) & 82.410 & 84.807 & 84.640 & 84.427 & 86.870 & 88.484 & 86.790 & 88.271 \\
\hline \multirow[t]{3}{*}{$r_{3}$} & Initial position & 87.400 & 93.860 & 98.180 & 93.289 & 87.590 & 94.041 & 95.600 & 93.466 \\
\hline & $r_{3}: F$ (Forward direction) & 85.460 & 102.846 & 85.680 & 97.529 & 84.990 & 96.509 & 81.520 & 96.994 \\
\hline & $r_{3}: B$ (Backward direction) & 99.350 & 91.413 & 87.670 & 94.428 & 96.340 & 93.059 & 97.580 & 92.629 \\
\hline \multirow[t]{3}{*}{$r_{1}$ and $r_{2}$} & Initial position & 97.440 & 94.385 & 107.590 & 113.468 & 112.750 & 111.784 & 112.810 & 110.333 \\
\hline & $r_{1}: F$ and $r_{2}: B$ & 108.830 & 85.519 & 113.600 & 89.064 & 113.860 & 88.755 & 113.110 & 87.108 \\
\hline & $r_{1}: B$ and $r_{2}: F$ & 107.990 & 114.134 & 113.330 & 113.313 & 113.450 & 116.829 & 112.720 & 114.918 \\
\hline \multirow[t]{3}{*}{$r_{1}$ and $r_{3}$} & Initial position & 107.490 & 108.712 & 104.150 & 109.092 & 88.690 & 109.788 & 96.480 & 109.845 \\
\hline & $r_{1}: F$ and $r_{3}: F$ & 113.620 & 112.861 & 121.600 & 110.534 & 114.050 & 111.636 & 124.360 & 112.528 \\
\hline & $r_{1}: B$ and $r_{3}: B$ & 103.910 & 106.575 & 88.690 & 108.336 & 96.140 & 107.757 & 98.770 & 108.193 \\
\hline \multirow[t]{3}{*}{$r_{2}$ and $r_{3}$} & Initial position & 99.130 & 109.382 & 81.220 & 90.025 & 78.790 & 90.953 & 82.430 & 90.015 \\
\hline & $r_{2}: B$ and $r_{3}: F$ & 76.580 & 87.847 & 77.300 & 86.275 & 73.440 & 87.118 & 74.370 & 87.810 \\
\hline & $r_{2}: B$ and $r_{3}: B$ & 86.820 & 81.173 & 79.100 & 82.077 & 81.950 & 81.775 & 81.100 & 82.219 \\
\hline \multirow[t]{7}{*}{$r_{1}, r_{2}$ and $r_{3}$} & Initial position & 81.240 & 90.231 & 107.780 & 92.710 & 109.260 & 93.573 & 109.110 & 104.509 \\
\hline & $r_{1}: F, r_{2}: B$ and $r_{3}: F$ & 94.510 & 87.336 & 102.890 & 88.848 & 98.760 & 92.660 & 103.390 & 91.037 \\
\hline & $r_{1}: B, r_{2}: F$ and $r_{3}: B$ & 110.340 & 115.071 & 111.120 & 114.891 & 113.590 & 112.385 & 114.390 & 112.977 \\
\hline & $r_{1}: F, r_{2}: F$ and $r_{3}: F$ & 113.550 & 120.141 & 115.180 & 117.695 & 109.530 & 117.464 & 119.210 & 121.473 \\
\hline & $r_{1}: B, r_{2}: F$ and $r_{3}: F$ & 85.160 & 121.085 & 107.390 & 117.248 & 97.110 & 116.580 & 86.080 & 120.983 \\
\hline & $r_{1}: B, r_{2}: B$ and $r_{3}: B$ & 80.000 & 85.105 & 87.050 & 90.305 & 87.530 & 91.695 & 78.610 & 84.248 \\
\hline & $r_{1}: F, r_{2}: B$ and $r_{3}: B$ & 113.880 & 85.490 & 109.490 & 94.561 & 108.610 & 91.375 & 117.910 & 81.643 \\
\hline
\end{tabular}

\subsection{Comparison study of end-effector rotation under ideal, feasible and experimental conditions}

The maximum angular rotation $(\theta)$ of the end-effector for the selected three manipulators was determined experimentally based on the observations mentioned under Tables 10, 11 and 12. The experimentally obtained maximum angular rotation was compared with the maximum angular rotation obtained under ideal and feasible conditions and mentioned in Table 14 which gives the maximum angular rotation data of the end-effector for each of the manipulators.

\section{Conclusion}

The major conclusions of this study have been outlined below:
1. The correlation between the active translational joint and the pose of the end-effector for various possible kinematic limb conditions has been derived.

2. The Jacobian matrices for the family of $U$-shape base 3-DOF planar parallel manipulators have been formulated.

3. The workspace area based on ideal and feasible conditions was predicted for all the eighteen unique PPMs. The manipulator with the maximum ideal and feasible workspace area is $\underline{P} P R-\underline{P} R P-\underline{P} R R$ with an area of $10277.58 \mathrm{~mm}^{2}$ and $9302.40 \mathrm{~mm}^{2}$, respectively. On the other hand, $\underline{P} R R-\underline{P} R R-\underline{P} R R$ had a minimum ideal workspace area of $393.80 \mathrm{~mm}^{2}$ and $\underline{P} R R-\underline{P} R R-\underline{P} R P$ had a minimum feasible workspace area of $83.89 \mathrm{~mm}^{2}$.

4. The three manipulators $\underline{P} P R-\underline{P} R P-\underline{P} R R, \underline{P} R P-\underline{P} P R-\underline{P} R P$ and $\underline{P} R P-\underline{P} P R-\underline{P} R R$ with higher workspace area of $9302.40 \mathrm{~mm}^{2}, 4893.50 \mathrm{~mm}^{2}$ and $4865.76 \mathrm{~mm}^{2}$ were further experimented. 
Table 12 Experimental workspace of C9 manipulator

\begin{tabular}{|c|c|c|c|c|c|c|c|c|c|}
\hline \multirow{3}{*}{$\begin{array}{l}\text { Actuators made of } \\
\text { SMA springs (condi- } \\
\text { tions) }\end{array}$} & \multirow{3}{*}{$\begin{array}{l}\text { Direction of the actuation } \\
\text { during heating of the SMA } \\
\text { springs }\end{array}$} & \multicolumn{8}{|c|}{ Position of the end-effector } \\
\hline & & \multicolumn{2}{|l|}{ Set-1 } & \multicolumn{2}{|l|}{ Set-2 } & \multicolumn{2}{|l|}{ Set-3 } & \multicolumn{2}{|l|}{ Set-4 } \\
\hline & & $\mathrm{Q}_{\mathrm{x}}(\mathrm{mm})$ & $\mathrm{Q}_{\mathrm{y}}(\mathrm{mm})$ & $\mathrm{Q}_{\mathrm{x}}(\mathrm{mm})$ & $\mathrm{Q}_{\mathrm{y}}(\mathrm{mm})$ & $\mathrm{Q}_{\mathrm{x}}(\mathrm{mm})$ & $\mathrm{Q}_{\mathrm{y}}(\mathrm{mm})$ & $\mathrm{Q}_{\mathrm{x}}(\mathrm{mm})$ & $\mathrm{Q}_{\mathrm{y}}(\mathrm{mm})$ \\
\hline \multirow[t]{3}{*}{$r_{1}$} & Initial position & 99.563 & 95.713 & 99.176 & 93.318 & 99.237 & 96.117 & 99.064 & 96.580 \\
\hline & $r_{1}: F$ (Forward direction) & 99.829 & 100.152 & 99.339 & 100.596 & 99.329 & 94.568 & 99.023 & 96.769 \\
\hline & $r_{1}: B$ (Backward direction) & 99.247 & 93.324 & 99.053 & 96.257 & 98.890 & 96.453 & 99.176 & 94.851 \\
\hline \multirow[t]{3}{*}{$r_{2}$} & Initial position & 98.819 & 96.959 & 98.503 & 91.713 & 98.645 & 92.952 & 98.543 & 90.578 \\
\hline & $r_{2}: F$ (Forward direction) & 100.767 & 123.887 & 100.634 & 124.468 & 101.063 & 122.321 & 100.114 & 119.876 \\
\hline & $r_{2}: B$ (Backward direction) & 98.921 & 86.692 & 99.227 & 86.312 & 98.788 & 86.842 & 99.227 & 84.156 \\
\hline \multirow[t]{3}{*}{$r_{3}$} & Initial position & 98.411 & 91.585 & 98.044 & 93.973 & 98.217 & 93.838 & 98.533 & 93.392 \\
\hline & $r_{3}: F$ (Forward direction) & 100.175 & 89.819 & 99.971 & 91.362 & 100.022 & 92.537 & 100.920 & 92.271 \\
\hline & $r_{3}: B$ (Backward direction) & 98.482 & 91.807 & 98.431 & 92.692 & 98.645 & 92.406 & 98.533 & 92.108 \\
\hline \multirow[t]{3}{*}{$r_{1}$ and $r_{2}$} & Initial position & 98.431 & 94.112 & 98.931 & 115.635 & 98.798 & 113.944 & 98.717 & 114.580 \\
\hline & $r_{1}: F$ and $r_{2}: B$ & 98.900 & 89.222 & 98.554 & 92.765 & 98.431 & 94.984 & 98.390 & 93.572 \\
\hline & $r_{1}: B$ and $r_{2}: F$ & 99.676 & 121.637 & 99.594 & 118.487 & 99.319 & 119.234 & 100.033 & 123.144 \\
\hline \multirow[t]{3}{*}{$r_{1}$ and $r_{3}$} & Initial position & 98.584 & 116.460 & 96.534 & 112.440 & 97.238 & 112.847 & 97.452 & 111.834 \\
\hline & $r_{1}: F$ and $r_{3}: F$ & 96.299 & 119.428 & 96.850 & 118.540 & 96.116 & 118.145 & 96.208 & 113.106 \\
\hline & $r_{1}: B$ and $r_{3}: B$ & 97.544 & 112.932 & 97.880 & 112.109 & 97.289 & 111.146 & 97.768 & 113.154 \\
\hline \multirow[t]{3}{*}{$r_{2}$ and $r_{3}$} & Initial position & 97.075 & 111.900 & 95.534 & 85.312 & 95.718 & 89.055 & 95.861 & 88.661 \\
\hline & $r_{2}: B$ and $r_{3}: F$ & 99.104 & 88.610 & 98.737 & 84.780 & 98.574 & 84.890 & 98.472 & 84.040 \\
\hline & $r_{2}: B$ and $r_{3}: B$ & 96.136 & 83.217 & 95.922 & 82.024 & 97.156 & 81.618 & 96.126 & 83.933 \\
\hline \multirow[t]{7}{*}{$r_{1}, r_{2}$ and $r_{3}$} & Initial position & 96.534 & 84.262 & 95.738 & 92.865 & 95.626 & 94.938 & 95.330 & 94.528 \\
\hline & $r_{1}: F, r_{2}: B$ and $r_{3}: F$ & 97.085 & 85.501 & 97.126 & 88.203 & 96.493 & 89.047 & 96.140 & 88.235 \\
\hline & $r_{1}: B, r_{2}: F$ and $r_{3}: B$ & 97.350 & 119.089 & 98.023 & 118.826 & 97.013 & 114.720 & 95.600 & 114.625 \\
\hline & $r_{1}: F, r_{2}: F$ and $r_{3}: F$ & 96.656 & 126.479 & 96.646 & 125.971 & 97.095 & 125.730 & 96.540 & 117.983 \\
\hline & $r_{1}: B, r_{2}: F$ and $r_{3}: F$ & 95.626 & 123.710 & 95.626 & 120.184 & 96.034 & 119.203 & 95.210 & 118.276 \\
\hline & $r_{1}: B, r_{2}: B$ and $r_{3}: B$ & 96.820 & 78.853 & 96.605 & 82.081 & 97.146 & 84.347 & 96.180 & 85.563 \\
\hline & $r_{1}: F, r_{2}: B$ and $r_{3}: B$ & 96.575 & 89.317 & 97.105 & 86.435 & 97.258 & 88.056 & 99.829 & 92.447 \\
\hline
\end{tabular}

5. The PPR-PRP-PRR manipulator was found to possess the highest experimental workspace area than any other combination.

6. The PPR-PRP-PRR manipulator was also found to possess the highest angular motion of $33^{\circ}$ based on the experiment conducted.
7. The developed micro-motion stage can be incorporated wherever $\mathrm{X}$ - and $\mathrm{Y}$-axis motion is required with micron-level accuracy.

The developed manipulator prototype can further be implemented for the process of micro-milling operation, 

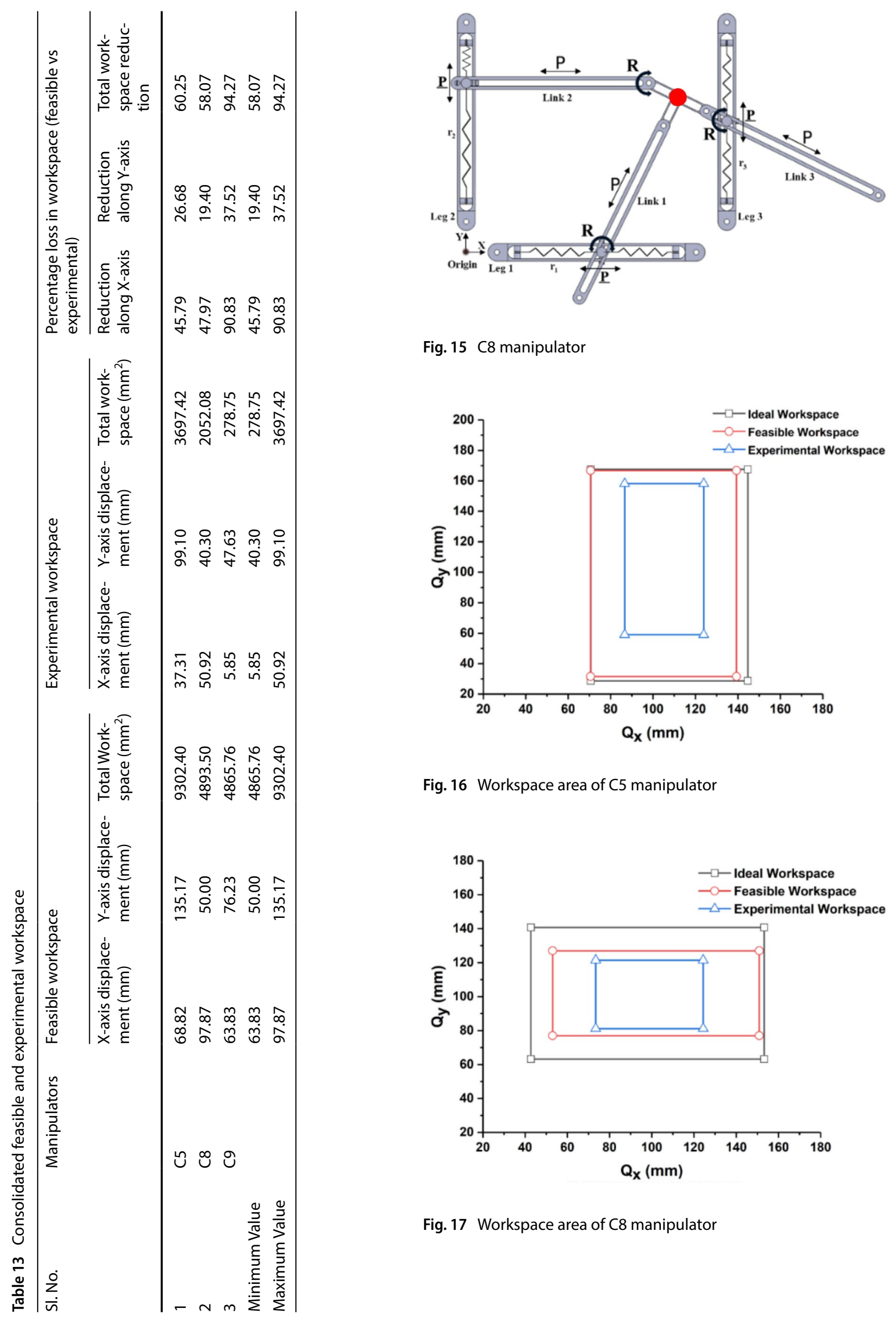

Fig. 15 C8 manipulator

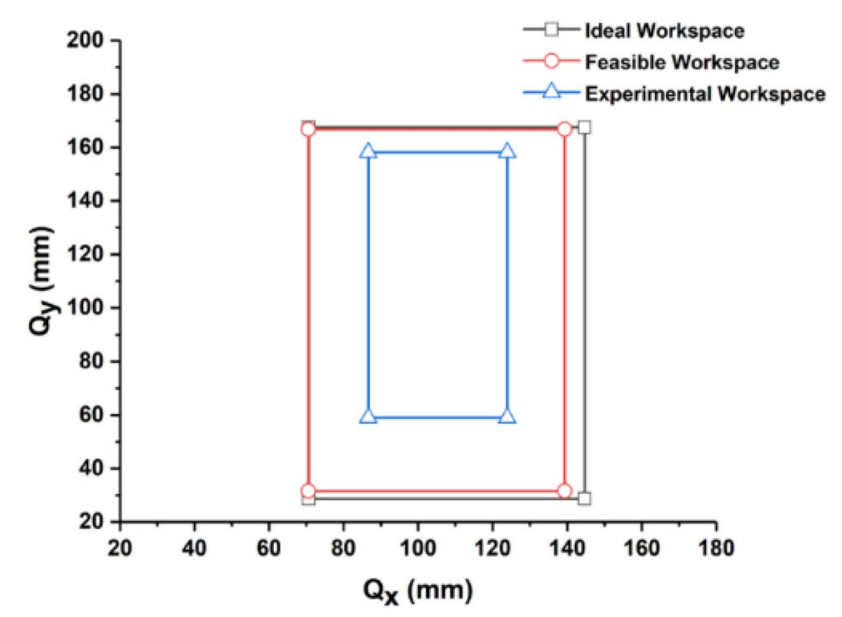

Fig. 16 Workspace area of C5 manipulator

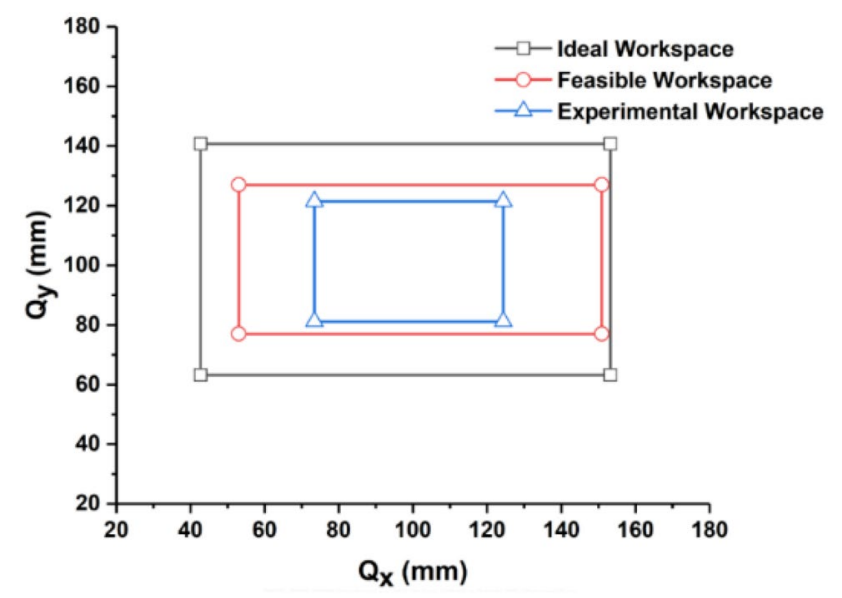

Fig. 17 Workspace area of C8 manipulator 


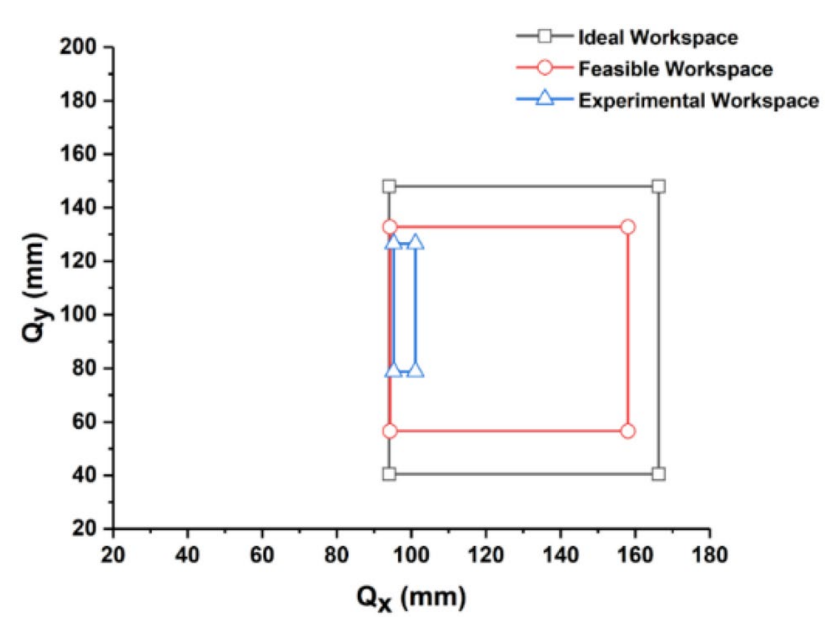

Fig. 18 Workspace Area of C9 Manipulator

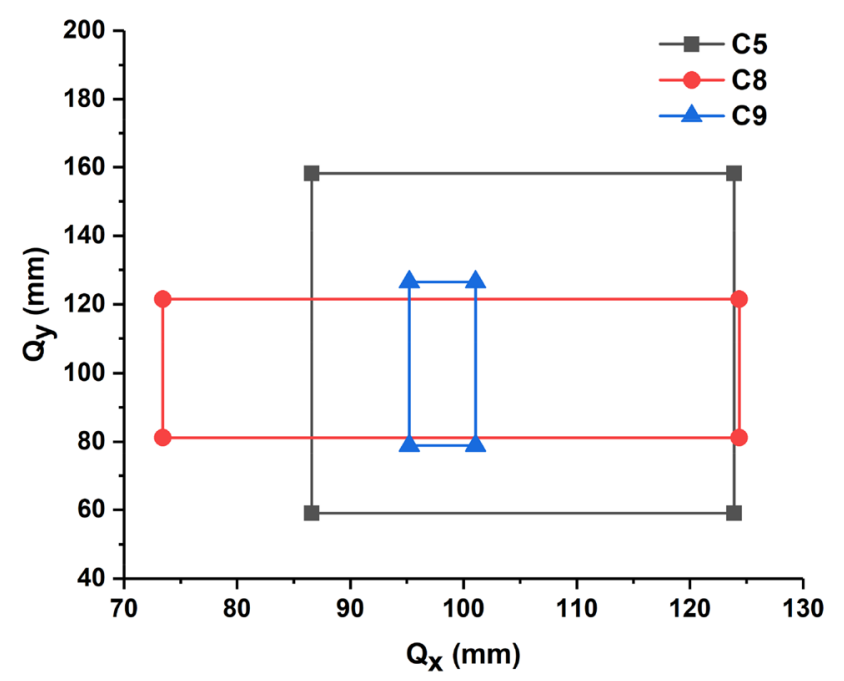

Fig. 19 Experimental workspace area of manipulators
micro-3D printer and other operations too. A three-axis motion stage with SMA spring-based smart actuator can be developed for various three-dimensional applications.

Acknowledgements The presented work in the paper is supported and funded by the CSIR-EMR-II, India (No. 22(0831)/19/EMR-II), and Start-up Research Grant, SERB, DST, India (No. SRG/2020/000491).

\section{Declarations}

Conflict of interest On behalf of all authors, the corresponding author states that there is no conflict of interest.

Open Access This article is licensed under a Creative Commons Attribution 4.0 International License, which permits use, sharing, adaptation, distribution and reproduction in any medium or format, as long as you give appropriate credit to the original author(s) and the source, provide a link to the Creative Commons licence, and indicate if changes were made. The images or other third party material in this article are included in the article's Creative Commons licence, unless indicated otherwise in a credit line to the material. If material is not included in the article's Creative Commons licence and your intended use is not permitted by statutory regulation or exceeds the permitted use, you will need to obtain permission directly from the copyright holder. To view a copy of this licence, visit http://creativecommons. org/licenses/by/4.0/.

\section{References}

1. Briot $S$, Bonev IA (2010) Are parallel robots more accurate than serial robots? Trans Can Soc Mech Eng 31:445-455

2. Dasgupta B, Mruthyunjaya TS (2000) The Stewart platform manipulator: a review. Mech Mach Theory 35:15-40

3. Merlet JP (2006) Parallel robots, 2nd edn. Springer, Netherlands

4. Patel Y, George P (2012) Parallel manipulators applications-a survey. Mod Mech Eng 2(3):57-64

5. Singh D, Singh Y (2018) Development and analysis of a five degrees of freedom robotic manipulator serving as a goalkeeper to train the football players. IOP Conf Ser Mater Sci Eng 402(1):012092

6. Staicu S (2009) Inverse dynamics of the 3-PRR planar parallel robot. Robot Auton Syst 57(5):556-563

7. Joubair A, Slamani M, Bonev IA (2012) A novel XY-Theta precision table and a geometric procedure for its kinematic calibration. Robot Comput Integr Manuf 28:57-65

8. Staicu S (2009) Inverse dynamics of the 3-PRR planar parallel robot. Robot Auton Syst 57:556-563
Table 14 Consolidated maximum end-effector rotation under ideal, feasible and experimental conditions

\begin{tabular}{|c|c|c|c|c|}
\hline \multirow[t]{2}{*}{ SI. No. } & \multirow[t]{2}{*}{ Manipulators } & \multicolumn{3}{|c|}{$\begin{array}{l}\text { Maximum end-effector angular motion analysis (in } \\
\text { degrees) }\end{array}$} \\
\hline & & Ideal condition & $\begin{array}{l}\text { Feasible condi- } \\
\text { tion }\end{array}$ & $\begin{array}{l}\text { Experimen- } \\
\text { tal condition }\end{array}$ \\
\hline 1 & $\mathrm{C} 5$ & 48.83 & 43.52 & 33.00 \\
\hline 2 & $\mathrm{C} 8$ & 38.43 & 37.52 & 16.00 \\
\hline 3 & C9 & 65.80 & 54.87 & 27.00 \\
\hline Minimum value & & 38.43 & 37.52 & 16.00 \\
\hline Maximum value & & 65.80 & 54.87 & 33.00 \\
\hline
\end{tabular}


9. Choi KB (2003) Kinematic analysis and optimal design of 3-PPR planar parallel manipulator. KSME Int J 17:528-537

10. Bai S, Caro S (2009) Design and analysis of a 3-PPR planar robot with U-shape base. In: ICAR International conference on advanced robotics, pp 1-6

11. Bonev IA (2010) Planar parallel mechanism and method. US Patent 7707907B2

12. Wu J, Wang J, Wang L, You Z (2010) Performance comparison of three planar 3 dof parallel manipulators with 4-RRR, 3-RRR and 2-RRR structures. Mechatronics 20(4):510-517

13. Rezaei A, Akbarzadeh A (2013) Position and stiffness analysis of a new asymmetric 2PRR-PPR parallel CNC machine. Adv Robot 27(2):133-145

14. Gogu G (2008) Structural synthesis of parallel robots. Part 1: methodology, 1st edn. Springer, Netherlands

15. Gogu G (2009) Structural synthesis of parallel robots. Part 2: translational topologies with two and three degrees of freedom, 1 st edn. Springer, Netherlands

16. Gogu G (2010) Structural synthesis of parallel robots. Part 3: topologies with planar motion of the moving platform, 1st edn. Springer, Netherlands

17. Khan WA, Krovi VN, Saha SK, Angeles J (2005) Recursive kinematics and inverse dynamics for a planar $3 R$ parallel manipulator. $J$ Dyn Syst Meas Control 127:529-536

18. Wenger $P$, Chablat $D$, Zein $M$ (2007) Degeneracy study of the forward kinematics of planar 3-RPR parallel manipulators. J Mech Des 129:1265-1268

19. Yu A, Bonev IA, Murray PZ (2008) Geometric approach to the accuracy analysis of a class of 3-dof planar parallel robots. Mech Mach Theory 43:364-375

20. Arakelian VH, Smith MR (2008) Design of planar 3-dof 3-RRR reactionless parallel manipulators. Mechatronics 18:601-606

21. Briot S, Bonev IA (2008) Accuracy analysis of 3-dof planar parallel robots. Mech Mach Theory 43:445-458

22. Staicu S (2008) Dynamics of a 3-RPR planar parallel robot. UPB Sci Bull Series D 70(3)

23. Yu A, Bonev IA, Zsombor-Murray P (2006) New XY-Theta positioning table with partially decoupled parallel kinematics. In: Proceedings of the IEEE international symposium on industrial electronics, pp 3108-3112

24. Caro S, Binaud N, Wenger P (2009) Sensitivity analysis of 3-RPR planar parallel manipulators. J Mech Des 131(12):121005

25. Wu J, Wang J, You Z (2011) A comparison study on the dynamics of planar 3-dof 4-RRR, 3-RRR and 2-RRR parallel manipulators. Robot Comput Integr Manuf 27(1):150-156

26. Wu G, Bai S, Kepler JA, Caro S (2012) Error modelling and experimental validation of a planar 3-PPR parallel manipulator with joint clearance. J Mech Robot 4(4):041008

27. Wu J, Li T, Wang J, Wang L (2013) Performance analysis and comparison of planar 3-dof parallel manipulators with one and two additional branches. J Intell Rob Syst 72:73-82

28. Caro S, Chablat D, Ur-Rehman R, Wenger P (2011) Multi-objective design optimization of 3-PRR planar parallel manipulators. In: 20th CIRP Design conference. (pp. 373-383)

29. Williams RL, Joshi AR (1999) Planar parallel 3-RPR manipulator. In: conference on applies mechanisms and robotics

30. Yang Y, Brien JF (2007) A case study of the planar 3-RPR parallel robot singularity free workspace design. In: Proceedings of IEEE international conference on mechatronics and automation. (pp. 1834-1838)

31. Staicu S (2009) Power requirement comparison in the 3-RPR planar parallel robot dynamics. Mech Mach Theory 44:1045-1057

32. Vinoth V, Singh Y, Mohan S (2014) Indirect disturbance compensation control of a planar parallel (2-PRP and 1-PPR) robotic manipulator. Robot Comput Int Manuf 30(5):556-564
33. Singh Y, Mohan S (2015) Inverse dynamics and robust sliding mode control of a planar parallel (2-PRP and 1-PPR) robot augmented with a nonlinear disturbance observer. Mech Mach Theory 92:29-50

34. Londhe PS, Singh Y, Mohan S, Patre B, Waghmare LM (2016) Robust nonlinear PID-like fuzzy logic control of a planar parallel (2PRP-PPR) manipulator. ISA Trans 63:218-232

35. Singh Y, Vinoth V, Kiran YR, Mohanta JK, Mohan S (2015) Inverse dynamics and control of a 3-DOF planar parallel robotic (U-Shaped 3-PPR) manipulator. Robot Comput Int Manuf 34:164-179

36. Singh $Y$ (2016) Performance investigations on mechanical design and motion control of planar parallel manipulators. Ph.D. Thesis, Indian Institute of Technology Indore.

37. Wu J, Wang J, Wang L, Li T (2009) Dynamics and control of a planar 3-DOF parallel manipulator with actuation redundancy. Mech Mach Theory 44:835-849

38. Wu J, Wang $D$, Wang $L$ (2015) A control strategy of a two degrees-of-freedom heavy duty parallel manipulator. J Dyn Syst Meas Control 137(6):061007

39. Wu J, Gao Y, Zhang B, Wang L (2017) Workspace and dynamic performance evaluation of the parallel manipulators in a spraypainting equipment. Robot Comput Int Manuf 44:199-207

40. Merlet JP (1996) Direct kinematics of planar parallel manipulators. In: robotics and automation. In: Proceedings 1996 IEEE international conference on robotics and automation, pp 3744-3749

41. Chablat $D$, Wenger $P$ (2007) The kinematic analysis of a symmetrical three-degree-of-freedom planar parallel manipulator. CoRR

42. Merlet JP, Gosselin CM, Mouly N (1998) Workspaces of planar parallel manipulators. Mech Mach Theory 33(1-2):7-20

43. Wu G, Bai S, Kepler J (2015) Stiffness characterization of a 3-PPR planar parallel manipulator with actuation compliance. Proc Ins Mech Eng Part C J Mech Eng Sci 229(12):2291-2302

44. Bai S, Caro S (2009) Design and analysis of a 3-PPR planar robot with U-shape base. In: 2009 International conference on advanced robotics

45. Gosselin CM, Angeles J (1988) The optimum kinematic design of a planar three-degree-of-freedom parallel manipulator. J Mech Transm Autom Design 110(1):35-41

46. Mohanta J, Singh Y, Mohan S (2018) Kinematic and dynamic performance investigations of asymmetric (U-shape fixed base) planar parallel manipulators. Robotica 36(8):1111-1143

47. AbuZaiter A, Ng EL, Kazi S, Ali MSM (2015) Development of miniature stewart platform using $\mathrm{TiNiCu}$ shape-memory-alloy actuators. Adv Mater Sci Eng 928139

48. AbuZaiter A, Hikmat OF, Nafea M, Ali MSM (2016) Design and fabrication of a novel $X Y \theta z$ monolithic micro-positioning stage driven by NiTi shape-memory-alloy actuators. Smart Mater Struct 25(10):105004

49. Sreekumar $M$, Singaperumal $M$, Nagarajan $T$, Zoppi M, Molfino $R$ (2006) A compliant miniature parallel manipulator with shape memory alloy actuators. In: 2006 IEEE International conference on industrial technology, Mumbai. (pp. 848-853)

50. Singh Y, Mohan S (2017) Development of a planar 3PRP planar parallel manipulator using shape memory alloy spring based actuators. In: Proceedings of the advances in robotics (Proceeding AIR'17). pp 1-6

51. Singh $D$, Choudhury R, Singh $Y$, Mukherjee M (2020) Development and workspace analysis of smart actuation based planar parallel robotic motion stage. IOP Conf Ser Mater Sci Eng 912:032063

52. Paik JK, Wood RJ (2012) A bidirectional shape memory alloy folding actuator. Smart Mater Struct 21(6):065013 
53. Singh D, Singh Y, Mukherjee M (2021) Behaviour of NiTi based smart actuator for the development of planar parallel micromotion stage. In: Kalamkar V, Monokova K (eds) Advances in mechanical engineering. Lecture notes in mechanical engineering. Springer, Singapore, pp 221-228

54. Miková L, Medvecká-Beňová S, Kelemen M, Trebuňa F, Virgala I (2015) Application of shape memory alloy (SMA) as actuator. METABK 54(1):169-172

55. Leng J, Yan X, Zhang X, Huang D, Gao Z (2016) Design of a novel flexible shape memory alloy actuator with multilayer tubular structure for easy integration into a confined space. Smart Mater Struct 25(2):025007

56. Huang W (2002) On the selection of shape memory alloys for actuators. Mater Des 23(1):11-19
57. Sun L, Huang WM, Ding Z, Zhao Y, Wang CC, Purnawali H, Tang $C$ (2012) Stimulus-responsive shape memory materials: a review. Mater Des 33:577-640

58. DesRoches R, McCormick J, Delemont M (2004) Cyclical properties of superelastic shape memory alloy wires and bars. ASCE J Struct Eng 130(1):38-46

59. Khidir EA, Mohamed NA, Nor MJM, Mustafa MM (2008) A new method for actuating parallel manipulators. Sens Actuators $A$ Phys 147(2):593-599

60. Angeles J (2014) Fundamentals of robotic mechanical systems: Theory, methods, and algorithms, 4th edn. Springer, NY, USA

Publisher's Note Springer Nature remains neutral with regard to jurisdictional claims in published maps and institutional affiliations. 